\title{
Functional Anatomy of Macaque Striate Cortex. IV. Contrast and Magno-Parvo Streams
}

\author{
Roger B. H. Tootell, ${ }^{1}$ Susan L. Hamilton, ${ }^{1}$ and Eugene Switkes ${ }^{2}$ \\ 'Department of Psychology, University of California, Berkeley, California 94720, and ${ }^{2}$ Committee on Psychobiology, \\ Division of Natural Sciences, University of California, Santa Cruz, California 95064
}

\begin{abstract}
Macaque monkeys were shown achromatic gratings of various contrasts during ${ }^{14} \mathrm{C}$-2-deoxy-d-glucose (DG) infusion in order to measure the contrast sensitivity of different subdivisions of primary visual cortex. DG uptake is essentially saturated at stimulus contrasts of $50 \%$ and above, although the saturation contrast varies with layer and with different criteria. Following visual stimulation with gratings of $8 \%$ contrast, stimulus-driven uptake was relatively high in striate layer $4 \mathrm{Ca}$ (which receives primary input from the magnocellular LGN layers), but was absent in layer $4 \mathrm{Cb}$ (which receives primary input from the parvocellular layers). In this same (magnocellular-specific) stimulation condition, striate layers $4 B, 4 C a$, and 6 showed strong stimulus-induced DG uptake, and layers $2,3,4 \mathrm{~A}$, and 5 showed only light or negligible uptake. By comparison to other cases that were shown stimuli of systematically higher contrast, and to a wide variety of DG cases shown very different stimuli, it is evident that information derived from the magnocellular and parvocellular layers in the LGN remains partially, or largely, segregated in its passage through striate cortex, and projects in a still somewhat segregated fashion to different extrastriate areas. The sum of all available evidence suggests that the magnocellular information projects strongly through striate layers $4 \mathrm{Ca}, 4 \mathrm{~B}$, and 6 , with moderate input into the blobs in layers $2+3$, and to blob-aligned portions of layer 4A. Parvocellular-dominated regions of striate cortex include both the blob and interblob portions of layers $2+3,4 \mathrm{~A}, 4 \mathrm{Cb}$, and 5 . Because the major striate input to $\mathbf{V} 2$ arrives from striate layers $2+3$, and because the major striate input to MT originates in layer $4 \mathrm{~B}$ and 6 , it appears that area V2 receives information derived largely from the parvocellular LGN layers, and that area MT receives information derived mainly from the magnocellular layers.
\end{abstract}

In all mammals, the LGN can be divided into 2 or more layers on the basis of cytoarchitectonic criteria, as well as into laminar divisions based on differcnces in cyc input. In the macaque, 4 parvocellular (dorsal) layers and 2 magnocellular (ventral) layers are found in each nucleus.

\footnotetext{
Received July 2, 1986; revised June 22, 1987; accepted June 22, 1987.

We thank Russell L. De Valois for his generosity in supporting this long series of experiments. This work was supported by United States Public Health Service Grants EY-00014 and EY-02050 and National Science Foundation Grants BNS 82-02275 and BNS 78-86171.

Correspondence should be addressed to Roger B. H. Tootell at his present address: Department of Neurobiology, Harvard Medical School, 25 Shattuck St. Boston, MA 02115.

Copyright (C) 1988 Society for Neuroscience $0270-6474 / 88 / 051594-16 \$ 02.00 / 0$
}

Cells in the magno- and parvocellular layers differ from each other functionally as well as morphologically. In general, parvocellular cells are highly sensitive to variations in stimulus color, while magnocellular cells are not (De Valois et al., 1958; Wiesel and Hubel, 1966; Schiller and Malpeli, 1978). The luminance contrast sensitivity of magnocellular cells is much higher than that of parvocellular cells (Sperling et al., 1978; Kaplan and Shapley, 1982; Hicks et al., 1983; Derrington and Lennie, 1984). "Y" cells are found either exclusively (Dreher et al., 1976; Schiller and Malpeli, 1978) or preferentially (Kaplan and Shapley, 1982; Derrington and Lennie, 1984) in the magnocellular layers, depending on the criteria used to classify these cells (for review, see Shapley and Perry, 1986). According to several reports, cells in the magnocellular layers are more phasic, and have a higher optimal temporal modulation than do parvocellular cells (Wiesel and Hubel, 1966; Schiller and Malpeli, 1978; Hicks et al., 1983; Derrington and Lennie, 1984).

Cells in the parvocellular and magnocellular layers of the LGN project in a strictly segregated fashion to striate layers $4 \mathrm{Cb}$ and $4 \mathrm{Ca}$, respectively. Minor projections terminate in other layers as well (Hubel and Wiesel, 1972; Hendrickson et al., 1978; Horton, 1984). However, it is not clear what happens to these carefully segregated inputs in subsequent striate layers. It is improbable that information that is so carefully segregated at earlier levels is connected randomly in striate cortex, but it has been difficult to trace the fate of information derived from magno- and parvocellular LGN layers through extragranular striate layers in any exact way.

The issue is an important one because it has become increasingly obvious that cortical visual areas to which striate cortex projects are also distinct from one another, both functionally and anatomically. For instance, cells in area MT are almost uniformly direction-selective and color-insensitive (Zeki, 1974; Van Essen et al., 1981; Maunsell and Van Essen, 1983). In comparison, cells in another striate-recipient area, V2, are quite different: they are often color-selective, infrequently directionselective, and sometimes disparity-sclcctivc (Zeki, 1983; Burkhalter and Van Essen, 1982; Van Essen and Maunsell, 1983; DeYoe and Van Essen, 1985; M. S. Livingstone and D. H. Hubel, unpublished observations).

Since different striate layers project to these functionally unique extrastriate areas, it is possible that information that is segregated in parvocellular and magnocellular LGN layers remains distinct in different striate layers and is relayed in parallel to distinct extrastriate areas. The alternative possibility is that the magnocellular and parvocellular information is recombined along entirely unknown lines in striate cortex, and then sent on in 
transformed form to the various extrastriate areas. By looking carefully at the flow of magnocellular and parvocellular information in striate cortex, we hoped to discriminate between these 2 possibilities.

The obvious way to analyze the projection of magnocellular and parvocellular pathways through striate cortex would seem to be with HRP or other anatomical tracers. However, the architecture of striate cortex is so intricate that it has been difficult to define all the important intrinsic connections. For instance, no direct information is yet available on the intrinsic input to the blobs, or into the interblob regions, within either layer 2, 3, 5 , or 6 (Livingstone and Hubel, 1984b; Blasdel et al., 1985; Fitzpatrick et al., 1985). On the other hand, such a maze of connections has now been demonstrated between the different striate layers that it is difficult to know which are relevant for a given functional circuit. That is, a given functional circuit could be channeled over a much simpler subset of the possible connections demonstrated within striate cortex.

In order to analyze the flow of magno- and parvocellular information through striate cortex, we have instead used the ${ }^{14} \mathrm{C}$-2-deoxy- $d$-glucose (DG) technique, coupled with specific visual stimulation, in an approach that can be very loosely described as a "functional HRP." In this specific study, achromatic visual stimuli of low $(<10 \%)$ contrast were used to selectively stimulate magnocellular inputs to striate cortex, and DG was injected to label those cell regions throughout striate and extrastriate cortex that are activated by the low-contrast (magno-specific) visual stimulus.

This particular kind of visual stimulus was chosen because single-unit electrophysiological studies indicate that the luminance contrast sensitivity of parvocellular LGN cells (and hence their efferents) is quite poor. According to these reports, parvocellular cells do not respond to stimulus contrasts below about $10-12 \%$, even when the temporal and spatial aspects of the stimuli are optimized. By comparison, magnocellular cells (as well as the whole monkey) are apparently scnsitive to contrasts as low as 1\% (Sperling et al., 1978; Kaplan and Shapley, 1982; Hicks et al., 1983; Derrington and Lennie, 1984; see also Blasdel and Fitzpatrick, 1984).

The initial finding that magnocellular (but not parvocellular) cells respond at stimulus contrasts below about $10 \%$ was serendipitous (Sperling et al., 1978; Kaplan and Shapley, 1982). Subsequent electrophysiological reports (Hicks et al., 1983; Blasdel and Fitzpatrick, 1984; Derrington and Lennie, 1984) have supported the initial finding, but it remains possible that the apparent difference in contrast sensitivity is in fact due to microelectrode sampling biases of some sort. By using deoxyglucose to measure levels of neural activity in response to different stimulus contrasts, we eliminated the possibility of such a sampling bias because DG measurements presumably reflect the activity of all cells activated by the stimulus.

In addition, by stimulating with selectively higher contrasts in adjacent, nonoverlapping portions of the receptive field, we have been able to quantitatively measure the contrast gain function of cells in different striate layers. Such a selective measure of the contrast gain function would be much harder to achieve using the single-unit technique, and it is directly relevant to a quantitative analysis of striate visual processing. For instance, laminar variation in the contrast gain might be expected in a straightforward way from the wide variation in contrast thresholds of magnocellular and parvocellular inputs to striate cortex. In the one previous single-unit study of contrast gain in this area (in which laminar position was not assessed), wide variability of both the contrast gains and thresholds was evident (Albrecht and Hamilton, 1982). Such apparent variability might simply indicate a difference in the contrast gain functions in different laminae (or, for that matter, within blob-versus-interblob compartments within a lamina). DG data from the present study support this idea.

\section{Materials and Methods}

The general surgical and histological procedures used in this study are identical to those described in the first paper of this series (Tootell et al., 1988a). In the present experiment, 3 macaque monkeys ( $2 M$. assamensis and $1 M$. cynomolgus) were used in DG tests using low-contrast visual stimuli. A much larger number of monkeys (also used in related studies) were shown high-contrast stimuli. An acrylic head pedestal was implanted on each monkey about a week before the main DG experiment. During the later experiment, the animals were anesthetized (1-2 $\mathrm{mg} / \mathrm{kg} / \mathrm{hr}$ morphine sulfate, sodium pentobarbital as needed, and 75/ $25 \%$ nitrous oxide/oxygen), paralyzed $(10-20 \mathrm{mg} / \mathrm{kg} / \mathrm{hr}$ gallamine triethiodide and $1-3 \mathrm{mg} / \mathrm{kg} / \mathrm{hr}$ tubocurarine), and artificially respired. Clear contact lenses of the appropriate curvature were placed on the cornea, and $3 \mathrm{~mm}$ artificial pupils were inserted in front of the lens, centered on the optic axis. The eye(s) was focused and optically arranged so that the foveal projection of each eye (or, in monocular experiments, the open eye) was centered on a stimulus screen. In one case, the apparent foveal projection was confirmed by electrophysiological recording from foveal receptive fields. Stimuli were presented on a Tektronix 654 or 690 color monitor driven by a Nova $4 \mathrm{X}$ computer and a modified Lexidata image processor. Stimuli could be varied in orientation, spatial and temporal frequency, color, direction, etc. Exact stimulus parameters are described more fully below. A $50-12.5 \mu \mathrm{Ci} / \mathrm{kg}$ dose of $\mathrm{DG}$ was injected while the monkeys viewed each stimulus pattern. Monkeys were then euthanized and transcardially perfused with a phosphate-buffered formalin solution, and the brains removed. The opercular striate cortex of each hemisphere was dissected free and frozen while in a flattened state, then sectioned in a cryostat. All sections were cut parallel with the flattened cortical surface. Subsequent autoradiographic processing was standard, with modifications to permit cobalt-intensified cytochrome oxidase staining. For some quantitative analyses, optical densities measured in the autoradiographs were converted to relative levels of DG uptake by calibration against ${ }^{14} \mathrm{C}$ radioactive standards. In other analyses, the topography of DG periodicities was compared to that of cytox blobs in the same layer 3 sections by densitizing, spatially filtering (difference-of-Gaussians), aligning (to the nearest $25 \mu \mathrm{m}$ ), and overlaying the DG and cytox-stained images using a computer, and quantitatively analyzing the correspondence (Switkes et al., 1986).

All stimuli used in the present study were luminance-modulated square waves, moved across the screen at a velocity that was systematically varied within a physiological range. Further details of each stimulus (e.g., orientation, spatial frequency, and ocularity) are described case by case in Results.

The variable of chief interest in this study was contrast, defined conventionally as the difference in luminance (of black-white stripes) divided by twice the average luminance. The average luminance in these experiments was $25 \mathrm{ft}-\mathrm{L}$. Gratings of $8 \%$ contrast were used to functionally isolate magnocellular activity, and gratings of $18,28,38-40$, and $100 \%$ contrast were apposed to $8 \%$ gratings in split-field tests in order to sample different points along the contrast gain function. It should be noted that the contrast percentages used in this study apply only to periodic gratings; the contrast percentage given for aperiodic stimuli (such as single bars) will differ depending on the size of the area over which light intensity is averaged (Blasdel and Lund, 1983; Blasdel and Fitzpatrick, 1984). Although contrast gain mechanisms such as those in the cat (Ohzawa et al., 1982) have not been described in monkey striate cortex, we presented the visual stimuli for several minutes before the onset of DG infusion in order to allow for the possibility of contrast adaptation.

\section{Results}

Split-field test over a low-contrast range

We begin by describing results from one of 2 contrast split-field cases. The first case (43) was stimulated monocularly with a 
contrast of either $8,18,28$, or $38 \%$ in each of 4 quadrants. In all sectors, the stimulus was a square-wave grating of systematically varied spatial frequency $(0.7-3$ cycles $/ \mathrm{deg})$, moved across the screen at velocities that varied from 0.75 to $4.5 \mathrm{degs} / \mathrm{sec}$. The grating was shown at a single oblique orientation, so that orientation-specific DG differences between layers $4 \mathrm{Ca}$ and $4 \mathrm{Cb}$ could be used to differentiate these 2 layers. [Orientation-specific cells have been demonstrated in layer $4 \mathrm{Ca}$ but not $4 \mathrm{Cb}$ (Blasdel and Fitzpatrick, 1984; Livingstone and Hubel, 1984a), and deoxyglucose orientation columns have also been shown in $4 \mathrm{Ca}$ but not $4 \mathrm{Cb}$ (Livingstone and Hubel, 1984a; and unpublished observations).] Sectors of higher contrast were sandwiched between sectors of lower contrast so that the results of each stimulus sector could be clearly differentiated in the resultant autoradiograph. The borders of the 4 sectors were positioned so as to lie along orientations $45^{\circ}$ from the horizontal and vertical. Two of the (highest) contrast quadrants were thus represented bilaterally within striate cortex. This furnished a control for possible differences in histological processing between the 2 hemispheres. It also meant that the unshared (lower-contrast) quadrants were represented on proportionately more cortical area in each hemisphere.

A representative autoradiographic section from layer 3 of this animal is shown in Figure 1. The effects of (from top to bottom, Fig. $1 B) 38,8$, and $28 \%$ contrast are clearly differentiable. This is due to a near-total lack of stimulus-driven uptake produced by the $8 \%$ grating in layer 3 .

Figure 2 is a closeup of the border region between the 38 and $8 \%$ gratings at an eccentricity near $4^{\circ}$, shown in different layers. It has been shown that monocular stimulation normally produces dark DG ocular dominance strips in all layers, including layer 4Cb (Kennedy et al., 1976; Hendrickson and Wilson, 1979; Horton, 1984). Accordingly, when produced by stimuli of 38 , 28 , and $18 \%$ contrast in the present study, ocular dominance strips are also seen in layer $4 \mathrm{Cb}$ (cf. the upper half of Fig. 2, $D$, $E$ ). However, in layer $4 \mathrm{Cb}$ of the $8 \%$ contrast quadrant, therc are no signs of ocular dominance strips, even though the autoradiographs are photographed at a relatively high contrast. [Though overall uptake is higher in layer $4 \mathrm{Cb}$ than in some other striate layers, this occurs without any visual stimulation at all (see Tootell et al., 1988a), and hence the higher overall uptake does not indicate the presence of stimulus-related activity.] The lack of periodicities in $4 \mathrm{Cb}$ is all the more remarkable when we consider the clear DG periodicities in the $8 \%$ contrast quadrant in some layers above and below $4 \mathrm{Cb}$ (see Fig. 2, $A$, $E, F)$. Because the $8 \%$ contrast gratings produce no DG uptake at all in the layer of predominant parvocellular input, and because the low-contrast gratings do produce respectable uptake in layer $4 \mathrm{Ca}$, we assume that the DG activity found in the $8 \%$ contrast sector in other striate layers is derived from magnocellular inputs.

$\Lambda$ s we mentioned earlier, the $8 \%$ contrast grating produces very little DG uptake in layer 3 . This zone of light uptake extends from layer 1 through layers $2-3$, and includes layer $4 \mathrm{~A}$. The relative decrease of stimulus-related uptake in layer $4 \mathrm{~A}$ is in accord with the evidence that layer $4 \mathrm{~A}$ receives predominant input from the parvocellular, rather than the magnocellular, LGN layers (Hubel and Wiesel, 1972; Hendrickson et al., 1978). Layer $4 \mathrm{Ca}$ shows medium-contrast periodicities, and layer $4 \mathrm{~B}$ (to which 4Ca sends major projections) shows periodicities that are somewhat lighter in contrast. Layer 5 is characterized by periodicities that are negligible in this case, and very light in another case shown a similar stimulus. The low contrast of the layer 5 periodicities may reflect, in part, the strong projection from layers $2+3$ to layer 5 (Fisken et al., 1975; Blasdel et al., 1985), since layers $2+3$ are so lightly labeled in this stimulus condition. The periodicities in layer 6 are quite dark, approximately as dark as those in layer $4 \mathrm{Ca}$.

The pattern of DG uptake in the adjacent $38 \%$ contrast quadrant appears typical of those seen in previous cases stimulated with $100 \%$ contrast gratings. In this case, and in other animals stimulated with high-contrast gratings of a wide spatial frequency range, there is robust DG uptake throughout all cortical layers, including layers that are unlabeled or lightly labeled in the $8 \%$ cases (e.g., layers $2-4 \Lambda, 4 \mathrm{Cb}$, and 5 ).

Not surprisingly, striate regions stimulated by contrasts midway between 8 and $38 \%$ show a pattern of DG uptake that is somewhere between the 2 corresponding autoradiographic extremes. In this animal, the border between the 38 and the $18 \%$ contrast quadrants was mapped onto the other hemisphere, in striate regions that were retinotopically mirror-symmetrical to those at the $8-38 \%$ contrast border. The pattern of DG uptake in layers of particular interest at this border is shown in Figure 3. At contrasts of $18 \%$ (a mere $6-8 \%$ above reported parvocellular thresholds), there is clear stimulus-driven uptake in layer $4 \mathrm{Cb}$, as well as in layers $2+3$ and 5 . However, the ratio of uptake in these parvocellular-influenced layers $(4 \mathrm{Cb}, 4 \mathrm{~A}, 2,3$, and 5 ) to that of more magnocellular-influenced layers $(4 \mathrm{~B}, 4 \mathrm{Ca}$, and 6) still appears to be reduced relative to the laminar relationships seen in the adjacent, higher-contrast quadrant.

In order to quantify our impressions from all 4 contrast sectors, we measured the highest and lowest densities in each layer that contained periodicities, and the single density of each layer without periodicities. Within each layer, 40 samples were taken from areas of both highest and lowest density by sampling individual $50 \times 50 \mu \mathrm{m}$ areas of either high or low density, and averaging the data from each class. The difference (or lack thereof) between the densitics of stimulated and unstimulated periodicities is plotted in Figure 4 as "stimulus-driven" uptake. These data from each of the 4 contrast sectors form a rough contrast gain function in each layer.

In most layers, contrast gain functions are not perfectly linear; this may reflect measurement error as much as intrinsic variations in the slopes of the contrast gain function. The slopes of the contrast gain function in each layer are roughly parallel to each other, except for a possible saturation of the $4 \mathrm{Ca}$ function between the 28 and $38 \%$ samples. Because some stimulus-driven uptake appears in light ("unstimulated") ocular dominance strips in layer $4 \mathrm{Ca}$ (see Tootell et al., 1988a), the measurement of stimulus-driven uptake in this (but not other) layers may be systematically underestimated. This would rationalize the apparently higher uptake seen in layer 6 , compared to that in the geniculorecipient layer $4 \mathrm{Ca}$ (compare layers $4 \mathrm{Ca}$ and 6 at $38 \%$ in Fig. 4; see also Figs. 5 and 6).

\section{Split-field test over a wider contrast range}

Because it was important to be certain of the effects of contrasts of less than $10 \%$, and because the case described above gave no quantitative information about the effect of contrasts greater than $38 \%$, we presented another animal (case 35 ) with a stimulus similar to that described above, except that the contrasts corresponded to $8,18,40$, and $100 \%$ in the different stimulus quadrants. As before, this stimulus was presented monocularly and at a single (horizontal) orientation. In this animal, however, 

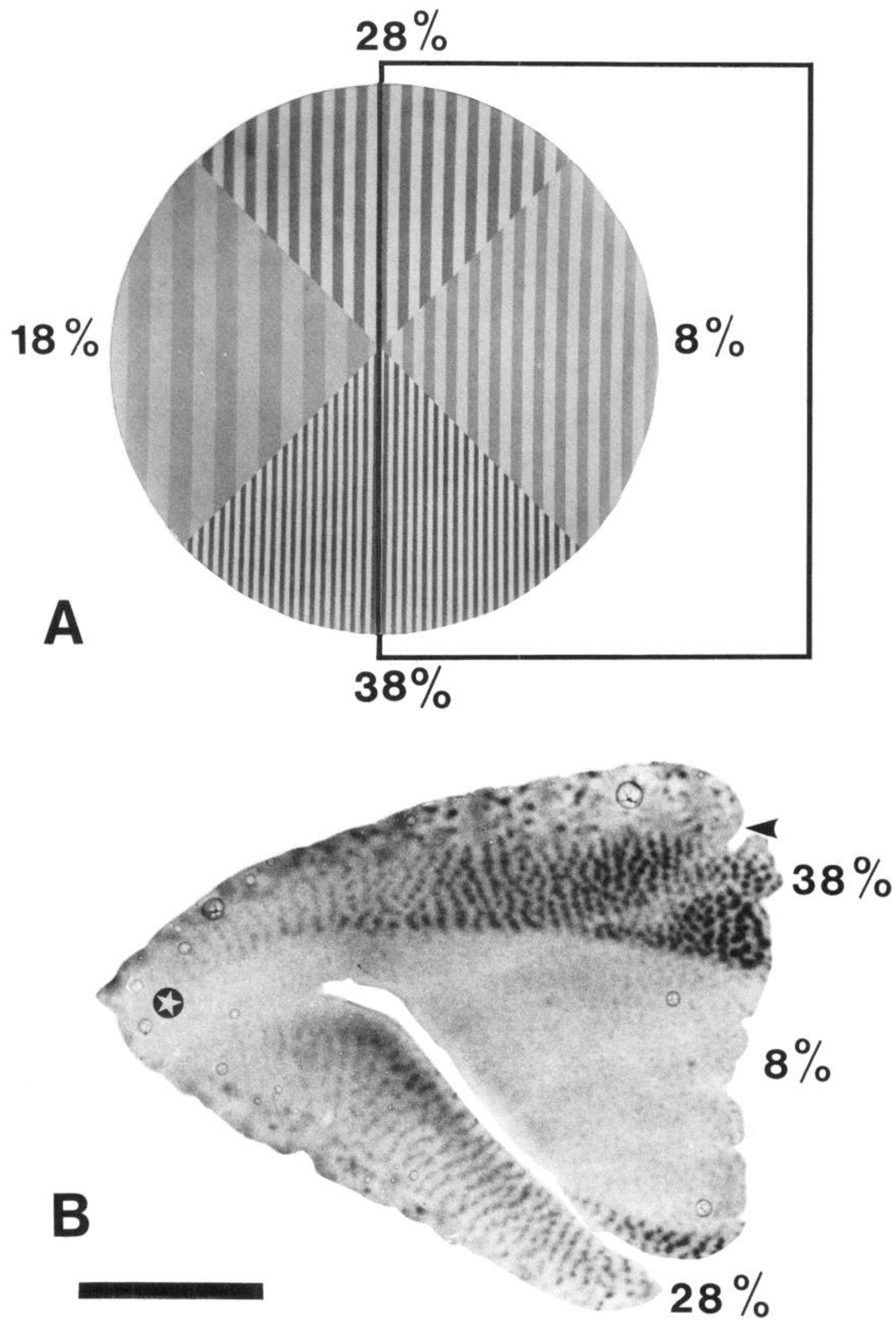

Figure 1. Split-field effects of different stimulus contrasts on striate DG uptake. $A$, The stimulus used in this case. Each of the 4 sectors was set to a different contrast [contrast $=\left(L_{\max }-L_{\min }\right) / 2 \cdot L_{\text {mean }}$ ]: clockwise from the top quadrant, the contrasts were $38,8,28$, and $8 \%$. The stimulus was presented monocularly, at a single contrast and a vertical orientation, but the spatial frequency of the gratings was systematically varied. The stimulus half on the right (enclosed within the large rectangle) projected to the left hemisphere $(B)$. The autoradiograph in $B$ was taken from a single layer 3 section, cut tangential to a flattened operculum. The foveal representation is represented by a star on the left, and the periphery towards the right. Specific sector boundaries (and their corresponding DG representations) are indicated in each panel. The different contrast sectors produced markedly different levels of DG uptake within layer 3. The dorsal V1-V2 border is indicated with a solid triangle towards the top of $B$. 

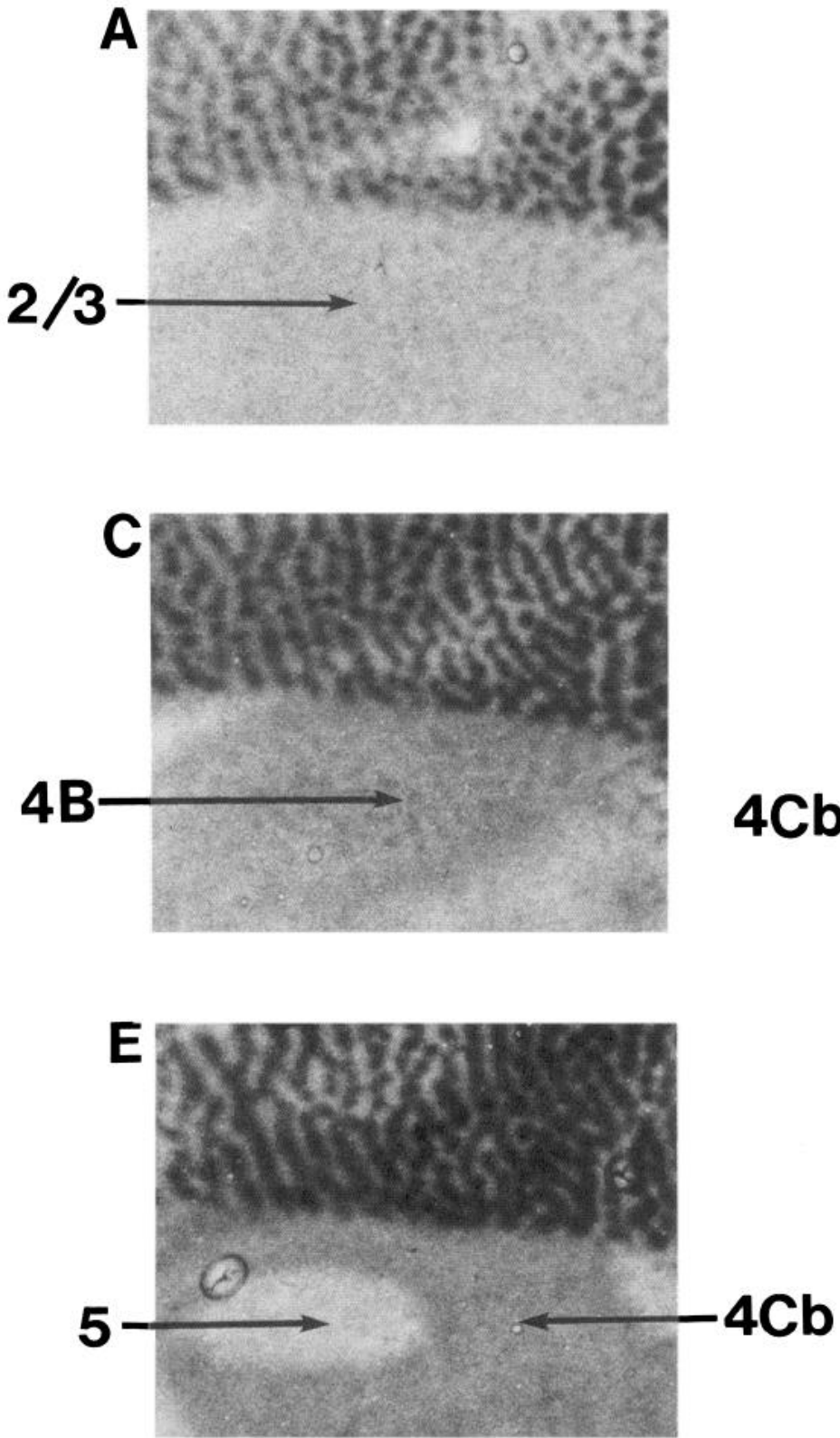

B
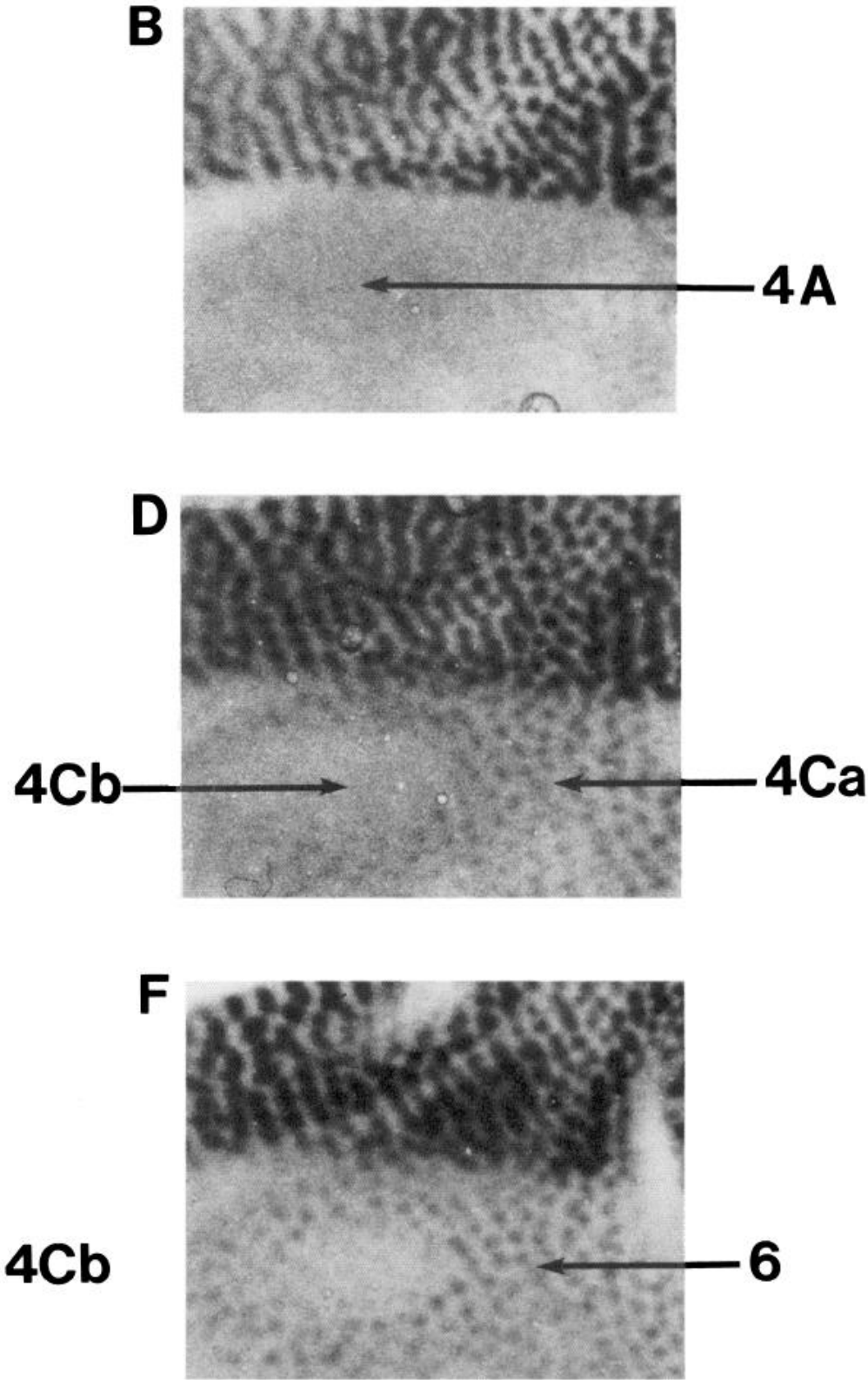

Figure 2. Laminar differences in DG uptake produced by a grating of $8 \%$ contrast. $A-F$, Taken from successively deeper sections at the parafoveal $38-8 \%$ contrast border described in Figure 1, towards the top right of $B$. The upper half of $A-F$ was thus stimulated by a grating of $38 \%$ (included mainly for comparison), and the bottom half by a grating of $8 \%$. Because the stimulus was presented monocularly and ocular dominance strips extend through all striate layers, the complete absence of ocular dominance strips in layer $4 \mathrm{Cb}(D)$ confirms electrophysiological evidence that parvocellular LGN cells do not respond to gratings of $8 \%$ contrast. The $8 \%$ grating also produces very little uptake in layers $2,3,4 \mathrm{~A}$, and $5(A, B$, $E$ ), which (in concert with other evidence) strongly suggests that these layers receive dominant innervation from $4 \mathrm{Cb}$ and the parvocellular stream. Uptake in layer 4B is moderate $(C)$, and in $4 \mathrm{Ca}$ and $6(D, F)$ it is reasonably robust. The relatively high stimulus-driven uptake in $4 \mathrm{Ca}$ confirms electrophysiological evidence that the magnocellular layers have a high-contrast sensitivity, and the moderate uptake in 4B presumably reflects a strong input from $4 \mathrm{Ca}$. The very high uptake in layer 6 certainly reflects a strong magnocellular influence, but it is not clear how many synaptic levels are interspersed between the geniculate input and the DG activation. Scale bar, $5 \mathrm{~mm}$.

the different stimulus sectors were separated along the vertical and horizontal meridians, so that 2 contrast sectors were fully mapped onto each hemisphere.

The results from the $8 / 40 \%$ border are shown in Figure 5. In general, the DG patterns are quite similar to those at the $8 / 38 \%$ border shown in Figure 2. Again, the $8 \%$ contrast grating produces no discernible uptake in layer $4 \mathrm{Cb}$, but it does produce significant uptake in $4 \mathrm{Ca}$. In the same quadrant, layers $2+3$ are again light, but in this animal there is some stimulus-driven uptake in these layers. The presence of some stimulus-related uptake in the upper layers in this and one other animal (and the absence of patterns in layer $4 \mathrm{Cb}$ ) suggests that magnocellular inputs do, in fact, reach the upper striate layers, although as a comparatively minor projection. This is in accord with recent HRP evidence (Blasdel et al., 1985). As in the previous case, layer 5 is lightly labeled, and the periodicities in layer 6 are 

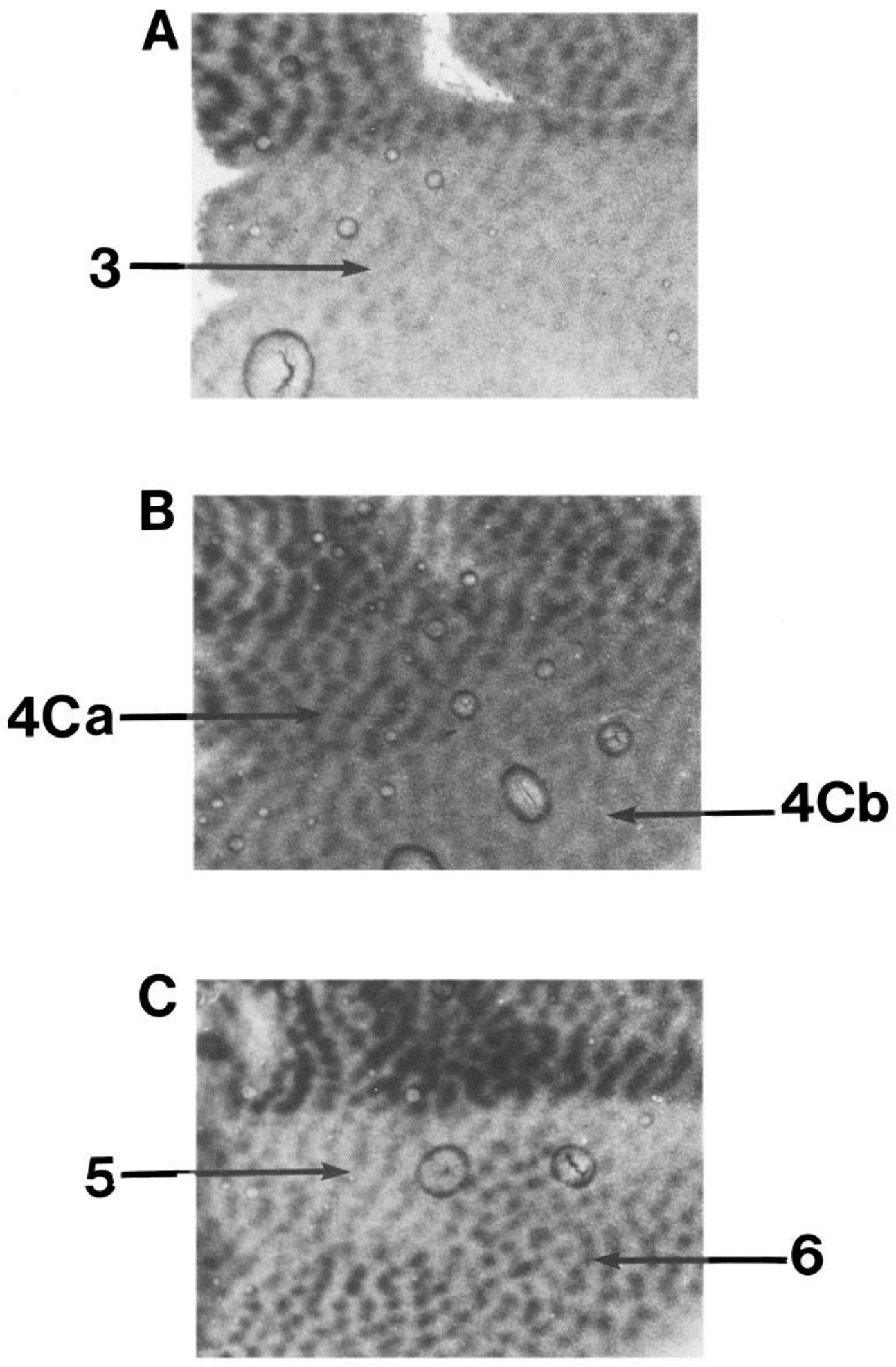

quite dark. Autoradiographic patterns in the 18 and $40 \%$ quadrants were similar to those seen in the previous animal (cf. Fig. 3).

Patterns produced by the $100 \%$ grating seemed indistinguishable from those produced by the $40 \%$ grating, except in layer $4 \mathrm{Cb}$. This would imply that the functional activity in most
Figure 3. Laminar differences in the pattern of DG uptake produced by grating of $18 \%$ contrast. The autoradiographs in $A-C$ were taken from successively deeper sections of the hemisphere contralateral to that described in Figure 2 (stimulus described in Fig. 1). The top third, $A-C$, shows the DG pattern produced by a grating of $38 \%$; the contrast grating appears throughout the middle and bottom portions. Patterns of uptake in significant layers are indicated by arrows. Parvocellular-influenced layers that were labeled very lightly (e.g., layers $3+5$ ) or unlabeled $(4 \mathrm{Cb})$ by grating contrasts of $8 \%$ show some obvious uptake following stimulation by gratings of $18 \%$ contrast. These results are in accordance with electrophysiological reports that the threshold contrast of parvocellular LGN cells is near $10 \%$. Scale bar, $5 \mathrm{~mm}$. striate layers is saturated by stimulus contrasts of $40 \%$ and above. To substantiate this observation, quantitative measurements of DG uptake were made in each of the 4 sectors, as in Figure 4 (see Fig. 6). DG uptake produced by the $100 \%$ grating is in fact very close to that produced by the $40 \%$ grating, except in parvorecipient layer $4 \mathrm{Cb}$. This indicates that DG uptake is essen- 
Figure 4. Densitometric measurements of stimulus-driven uptake in the case illustrated in Figures 1-3. "Stimulus-driven" uptake was calculated by subtracting the average uptake in the lightest regions from the average uptake in the darker regions within a given single layer. In layer $4 \mathrm{Cb}$, an $8 \%$ contrast grating produced no stimulus-driven uptake. In layers 3 and 5 , the $8 \%$ stimulus produced so little uptake that it could not be measured reliably, so it was assigned a value of zero. In other layers, and in other portions of striate cortex that were exposed to gratings of systematically higher contrast, stimulus-driven uptake can be plotted to form a rough contrast gain function for each layer. Within the range shown here, striate layers influenced strongly by the magnocellular LGN layers (e.g., 4B, $4 \mathrm{Ca}$, and 6) appear to have slopes that are roughly parallel to those for parvocellular-dominated layers (e.g., 3, 5, and $4 \mathrm{Cb}$ ), but displaced upwards along the $\mathrm{Y}$ axis.

tially saturated by stimulus contrasts near $50 \%$ in all layers except $4 \mathrm{Cb}$. The exact point at which uptake is "saturated," of course, varies with criterion as well as with layer.

\section{Binocular single-field test}

In the low-contrast sectors of the split-field tests, the periodicities produced by the monocular, single-orientation stimulation look like strings of beads. This implies that the dark DG periodicities are aligned on or near the cytochrome oxidase blobs in the extragranular stimulated eye dominance columns. In qualitative comparisons on a light box, these DG periodicities appeared to superimpose the cytochrome oxidase blobs lying in register with the stimulated eye dominance strips. In comparison, the DG uptake is highest in the interblob regions, or on the borders of the blobs, in a number of other animals shown similar stimuli near 100\% contrast (see Tootell et al., 1988a). It thus seems possible that the weak magnocellular projection to the upper layers is directed preferentially into (and through) the cytochrome oxidase blobs.

When DG activity in layer 3 is weak (as it is following stimulation with $8 \%$ gratings), the exact relationship of DG patterns to the blobs is clearest when visual stimulation is binocular and when orientation is systematically varied. This is the case because robust orientation- and eye dominance-specific uptake can otherwise swamp any lower-contrast, contrast-specific biases in DG uptake.

In order to clearly see the rclationship of magnocellular input to the upper-layer cytochrome oxidase blobs, we binocularly stimulated one monkey (case 45 ) with a square-wave grating of

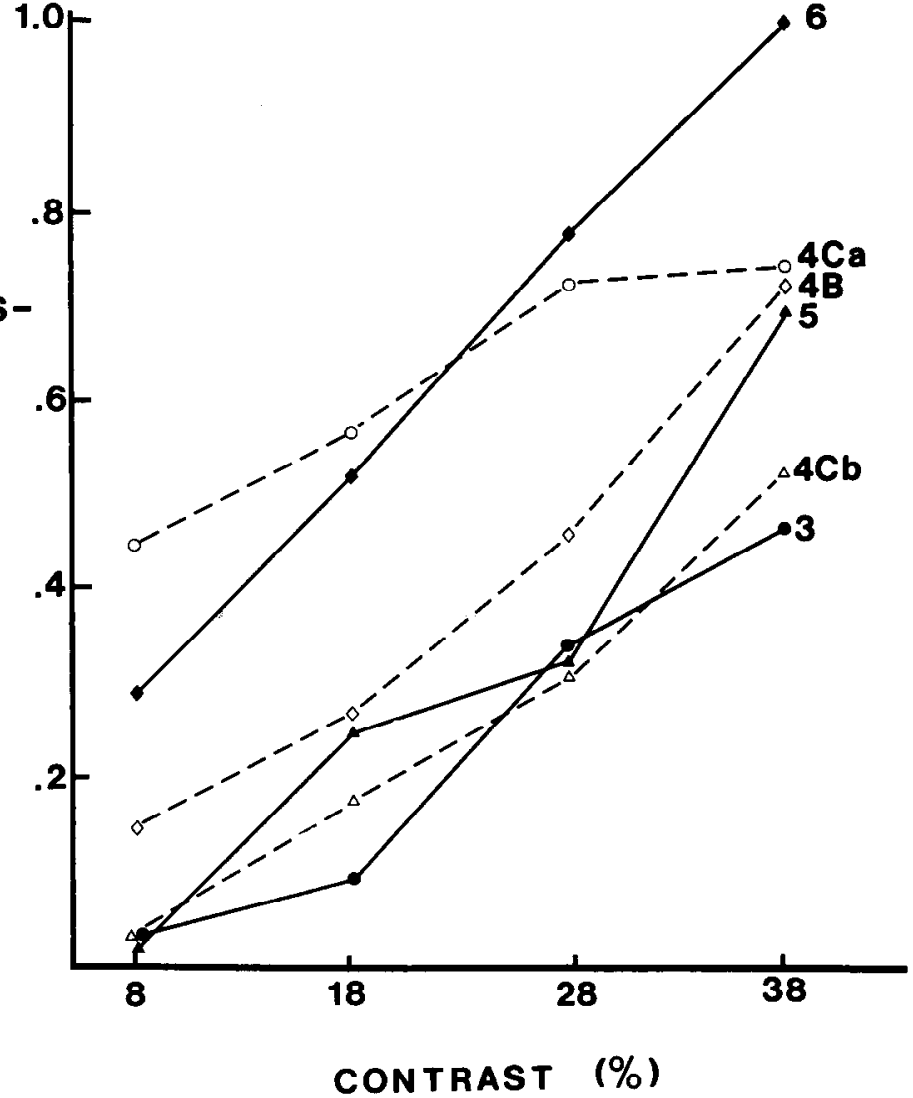

$8 \%$ contrast at all orientations. The spatial frequency of the grating was systematically varied between 1 and 4 cycles $/ \mathrm{deg}$, and the velocity was systematically varied between 0.5 and 3 degs/sec. The stimulus in this instance was limited to $10^{\circ}$ in horizontal extent, and the binocular disparity was not varied. The stimulus surrounding the $8 \%$ grating was a diffuse gray of the same mean luminance as that of the grating. Delimiting the stimulus to $5^{\circ}$ on each hemisphere allowed us to differentiate the $D G$ effects due to the low-contrast stimulus from those due to baseline uptake in cortical areas peripheral to those that were stimulated by the grating. The wide spatial frequency range of these gratings was similar to that used in the contrast split-field tests, and identical to that used in earlier baseline tests (see Tootell et al., 1988a). The advantage of choosing this spatial frequency range is that in the earlier tests these stimuli (at 100\% contrast) produced a relatively uniform pattern of DG uptake within parafoveal layer 3 . Results from this high-contrast animal are shown in Figure $7 A$. Thus, this spatial frequency range furnished a sensitively calibrated stimulus against which minor differences in activity between the high- and low-contrast stimuli could be measured relative to the cytochrome oxidase blobs.

In Figure $7 B$ we show the pattern of DG uptake produced by an $8 \%$ grating in layer 3 , taken from an identical parafoveal eccentricity. The region stimulated by an $8 \%$ grating is obviously more periodic than that produced by a higher-contrast grating of the same spatial configuration. In order to confirm that the dotted appearance in the $8 \%$ case is due to higher uptake in the cytox blobs (shown in Fig. 7C), we compared the autoradiographic and cytox-stained images quantitatively (Switkes et al., 

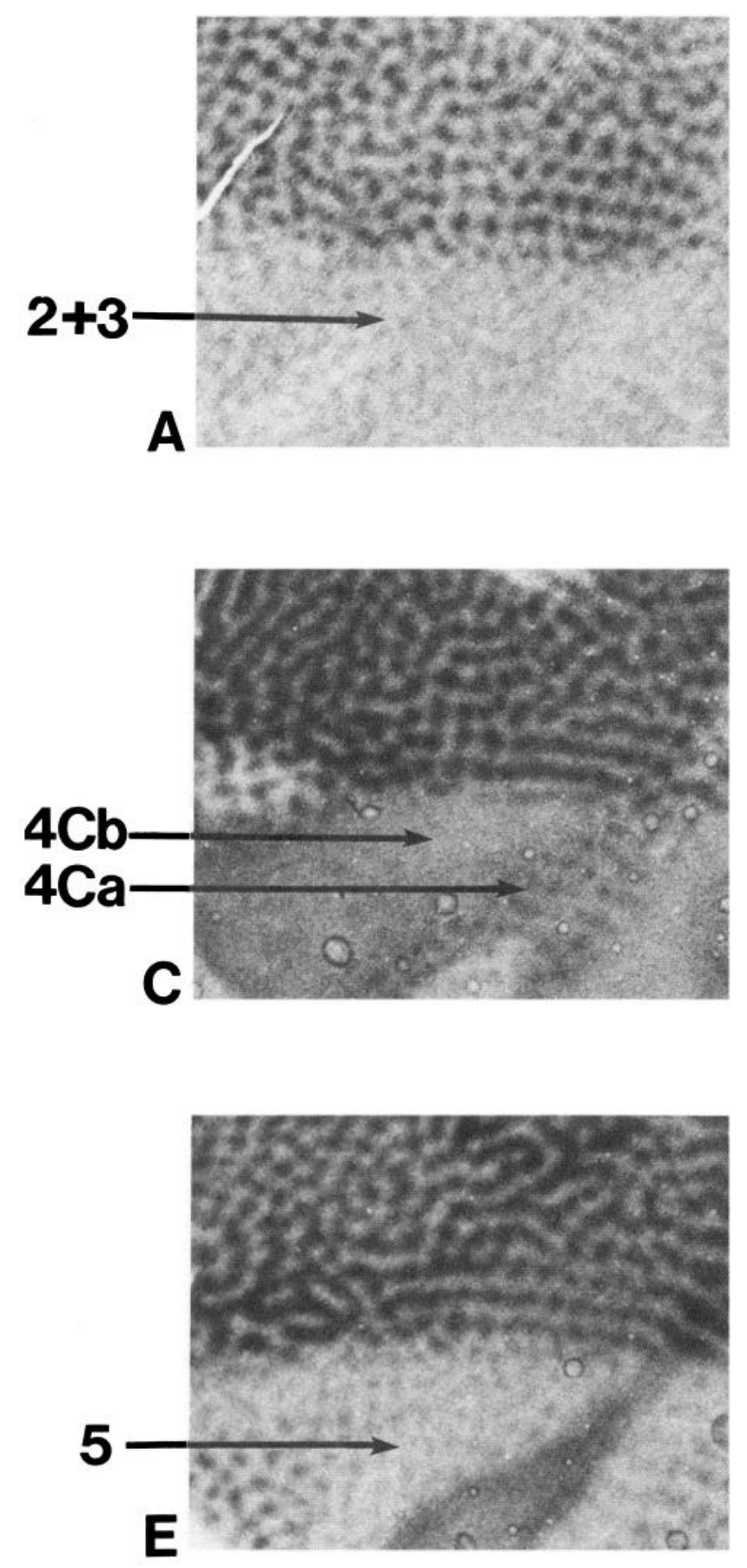
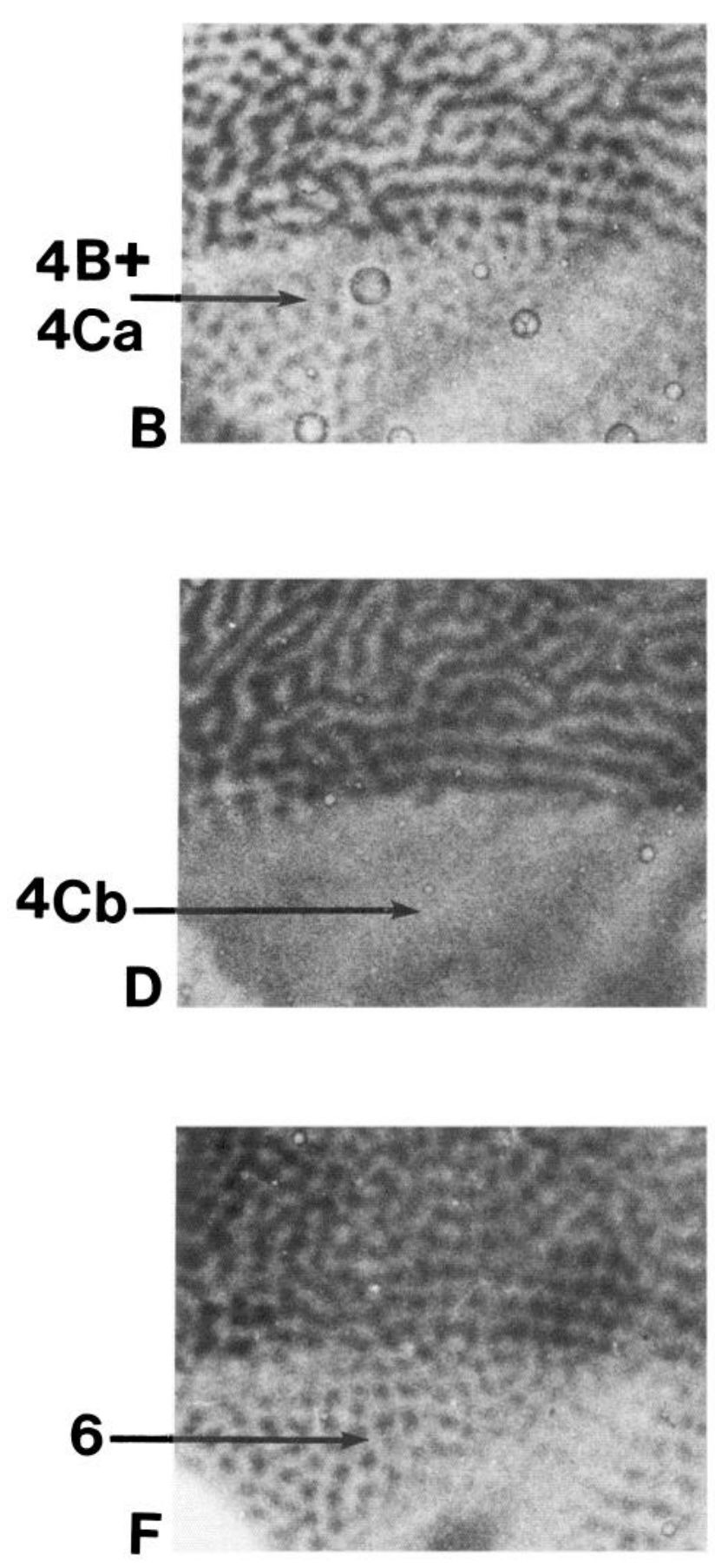

Figure 5. Laminar differences in uptake produced by an $8 \%$ grating. This case was similar in many respects to that described in Figure 2 . Again, the stimulus was a monocularly viewed grating of a single (horizontal) orientation, but with systematically varied spatial frequency. In the top of $A-F$, the cortex "saw" a grating of $40 \%$ contrast, and in the bottom half, a grating of $8 \%$ contrast. Again, there is virtually no stimulus-driven uptake in parvocellular-recipient layer $4 \mathrm{Cb}(C, D)$ and robust uptake in layers $4 \mathrm{~B}, 4 \mathrm{Ca}$, and $6(B, C, F)$. Uptake in layers $3,4 \mathrm{~A}$, and 5 of this case are extremely light (as in Fig. 2), but here the uptake is more clearly above unstimulated levels (see $A, E, F$ ). Scale bar, $5 \mathrm{~mm}$.

1986). For this analysis, both images were filtered and binarized into active and inactive regions. For the DG image, $28 \%$ of the area was above the active-inactive cut level, and $72 \%$ below. The cytox image was similarly divided at the $25 \%$ level. These binary levels were chosen to optimally match our subjective impressions of "high" and "low" DG uptake and cytox activity in the original sections. If there were a random geometric relationship between the high DG and cytox regions, then $28 \%$ of the high cytox-active regions should also show high DG uptake. In fact, however, the overlap between the DG and cytox 


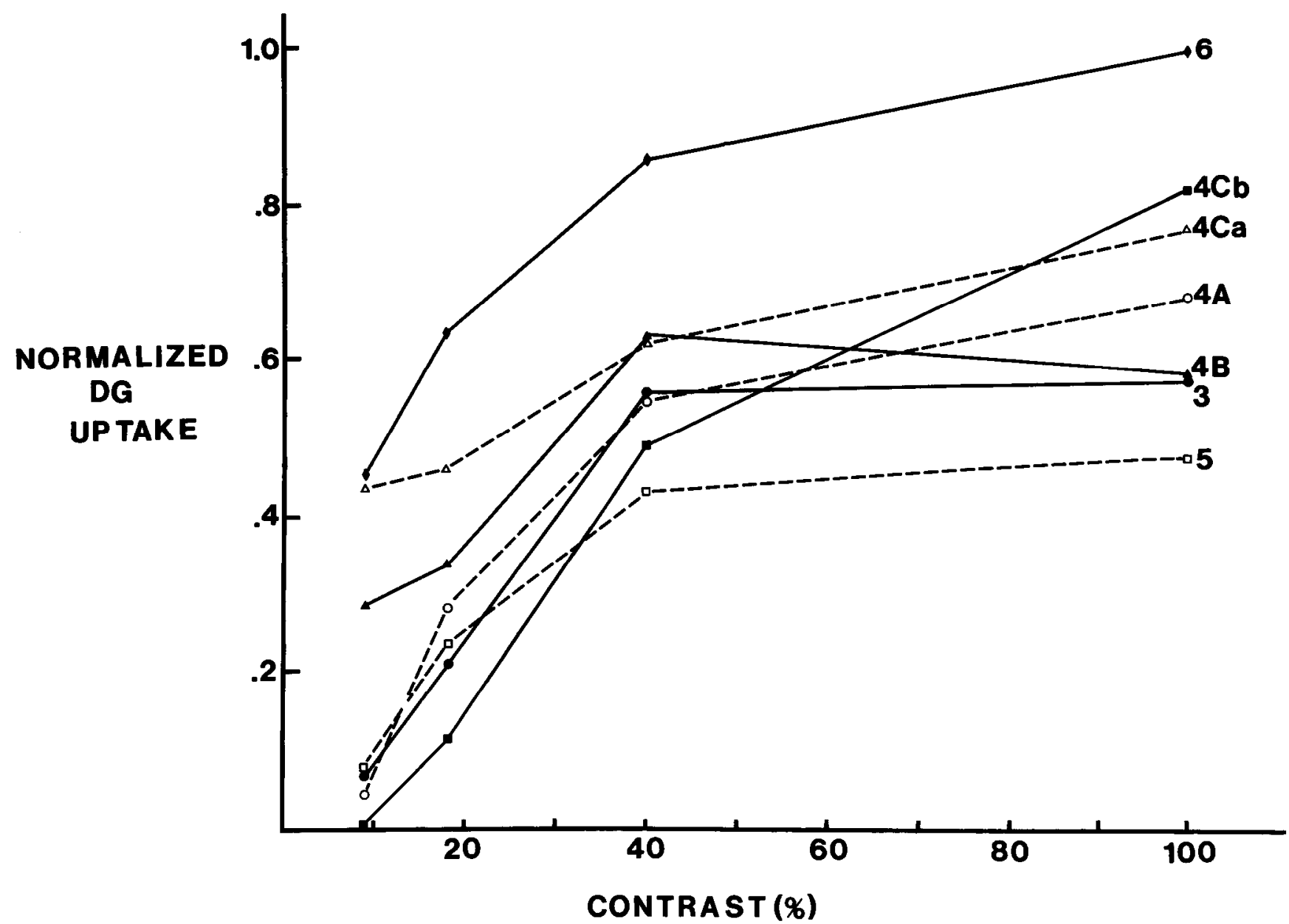

Figure 6. Densitometric measurement of stimulus-driven uptake in the case illustrated in Figure 5. The analysis is very similar to that shown in Figure 4, except that the DG contrast gain function was sampled at contrasts of $8,18,40$, and 100\%. Below $40 \%$, the data are in good agreement with those in Figure 4: stimulus-driven uptake in the magnocellular-dominated layers $(4 \mathrm{Ca}, 4 \mathrm{~B}$, and 6$)$ is higher at all contrasts than that in parvocellular-dominated layers $(3,5,4 \mathrm{~A}$, and $4 \mathrm{Cb}$ ). Between 40 and $100 \%$ contrast, the slope of the increase in uptake has a much shallower slope than below $40 \%$ contrast in all layers, except perhaps $4 \mathrm{Cb}$. This supports electrophysiological evidence suggesting a saturation of firing in many single units at stimuli above about $40 \%$ contrast.

corresponded to $45 \%$ of the cytox-active arca. When the samc DG and cytox images were randomly misaligned as a control procedure, the percentage of overlap fell to near $28 \%$, as one would expect.

Taken together, this evidence shows that the layer 3 DG periodicities lie preferentially on the cytox blobs. If we assume that magnocellular information projects to all the blobs, then, theoretically, $100 \%$ of the high cytox regions should also have been high DG regions. The very low amplitude of the original DG signal, and the accompanying ambiguity in dichotomizing active versus inactive regions, presumably accounts for this discrepancy at least to some extent.

Figure 8 shows the pattern of uptake produced in this case in other striate layers. As in the monocular, single-orientation cases stimulated with an $8 \%$ grating, significant stimulus-related uptake is visible in layer $4 \mathrm{Ca}$, but is not obvious in layer $4 \mathrm{Cb}$ (compare Fig. 8, $C$ and $D$ ). The blob bias seen in layers $2+3$ does not appear in layer 4B (not shown), nor in layer 5 . In layer 6 there is a very minor mottling of the pattern of DG uptake (perhaps biased towards the blobs), but it is a minor bias compared to that seen in layers $2+3$.

A number of aspects of this case imply that the $8 \%$ contrast stimulus came perilously close to significantly stimulating the parvoccllular inputs. The possibility thus arises that there is some interanimal variability in the contrast thresholds of parvocellular cells.

\section{Discussion}

\section{$D G$ contrast results and anatomical connections}

By using achromatic gratings of $8 \%$ contrast, it proved possible to selectively activate the magnocellular inputs to striate cortex, to the (apparently complete) exclusion of the more numerous parvocellular inputs. By labeling this activity with DG, we were able to describe the flow of magnocellular activity through subsequent striate layers, and into extrastriate cortex.

However, at some point one needs to consider the possibility that the few, very small cells in the intercalated LGN layers (that is, between the individual magno- and parvocellular layers) also respond to luminance contrasts lower than $10 \%$, and could therefore be contributing to the DG results. Unfortunately, in the macaque there are no electrophysiological data on the response of intercalated cells to various contrasts (or to any other stimulus, for that matter). It is not even clear that the intercalated layers project to striate cortex in the macaque. Faced with this dearth of evidence on the possible contribution of the in- 

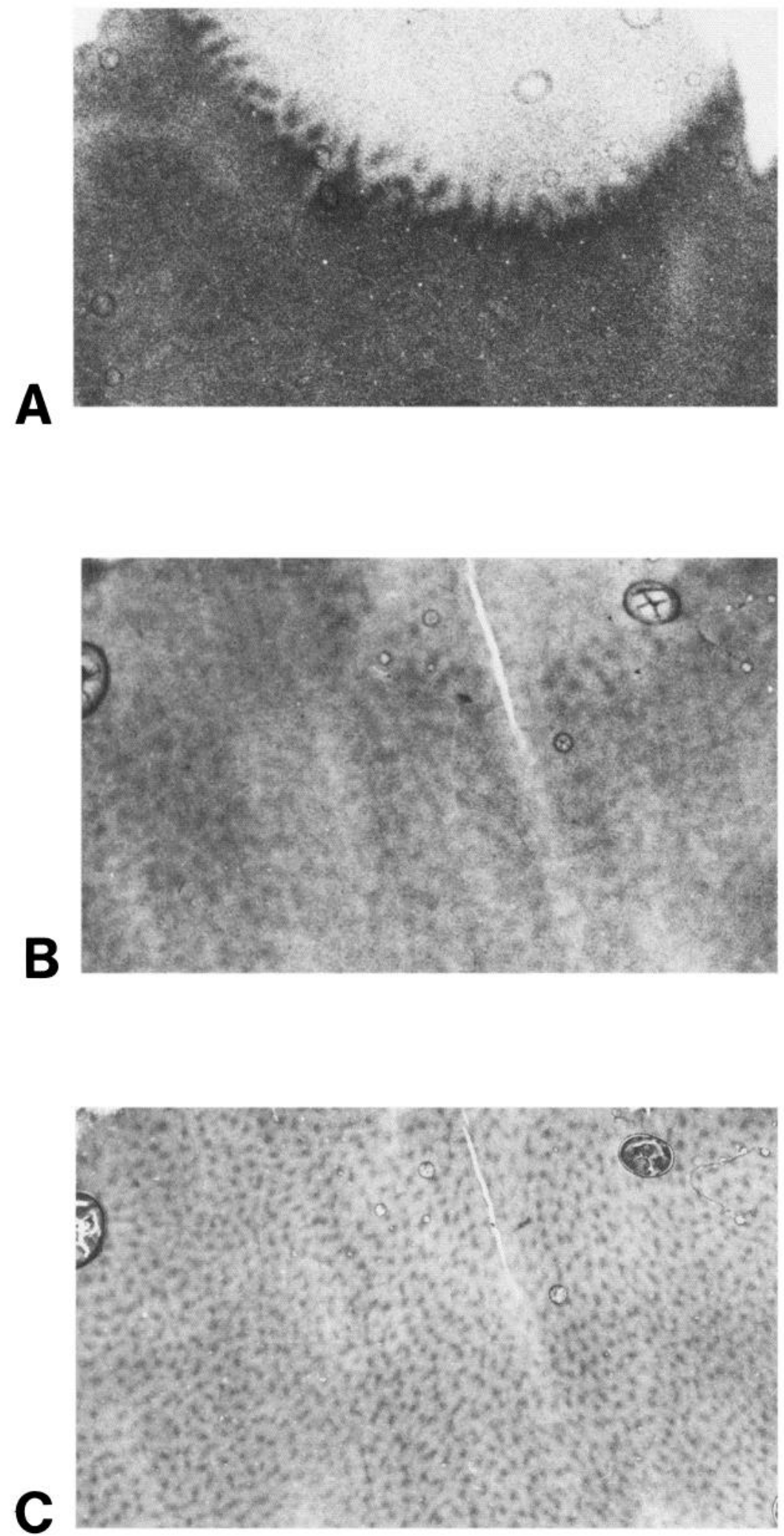

Figure 7. Evidence that information derived from the magnocellular LGN projects preferentially to the cytox blobs. $A, B$, The parafoveal layer 3 DG topography from 2 different cases stimulated with gratings that were very similar, except that the grating used to produce $A$ was set at $100 \%$ contrast, and that used for $B$ had a contrast of only $8 \%$. In both cases, the gratings were varied systematically in spatial frequency and were presented binocularly at all orientations. The horizontal extent of both gratings was restricted to about $5^{\circ}$, so that a crescent-shaped patch of visually unstimulated cortex appears on the parafoveal operculum (upper portion, $A$ and $B$ ). The DG uptake produced by the $100 \%$ contrast grating is topographically quite uniform within the binocularly stimulated area; uptake produced by the $8 \%$ grating is much spottier. The section that produced $B$ is shown in $C$ after staining for cytochrome oxidase. The DG spots lie in register with the cytochrome oxidase blobs. Scale bar, $5 \mathrm{~mm}$. tercalated LGN cells (which are not numerous in any case), it seems most sensible to keep the problem in mind but not worry unduly about it. In the remainder of this discussion, we will ignore it.

On the basis of the present DG results and other anatomical evidence, it appears that magnocellular activity spreads uniformly throughout layers $4 \mathrm{~B}, 4 \mathrm{Ca}$, and 6 in a fashion that is topographically relatively uniform. Magnocellular activity projects weakly into the blobs of layers $2+3$, but not into the interblob regions of these layers. Because layers $4 \mathrm{~B}$ and 6 project 

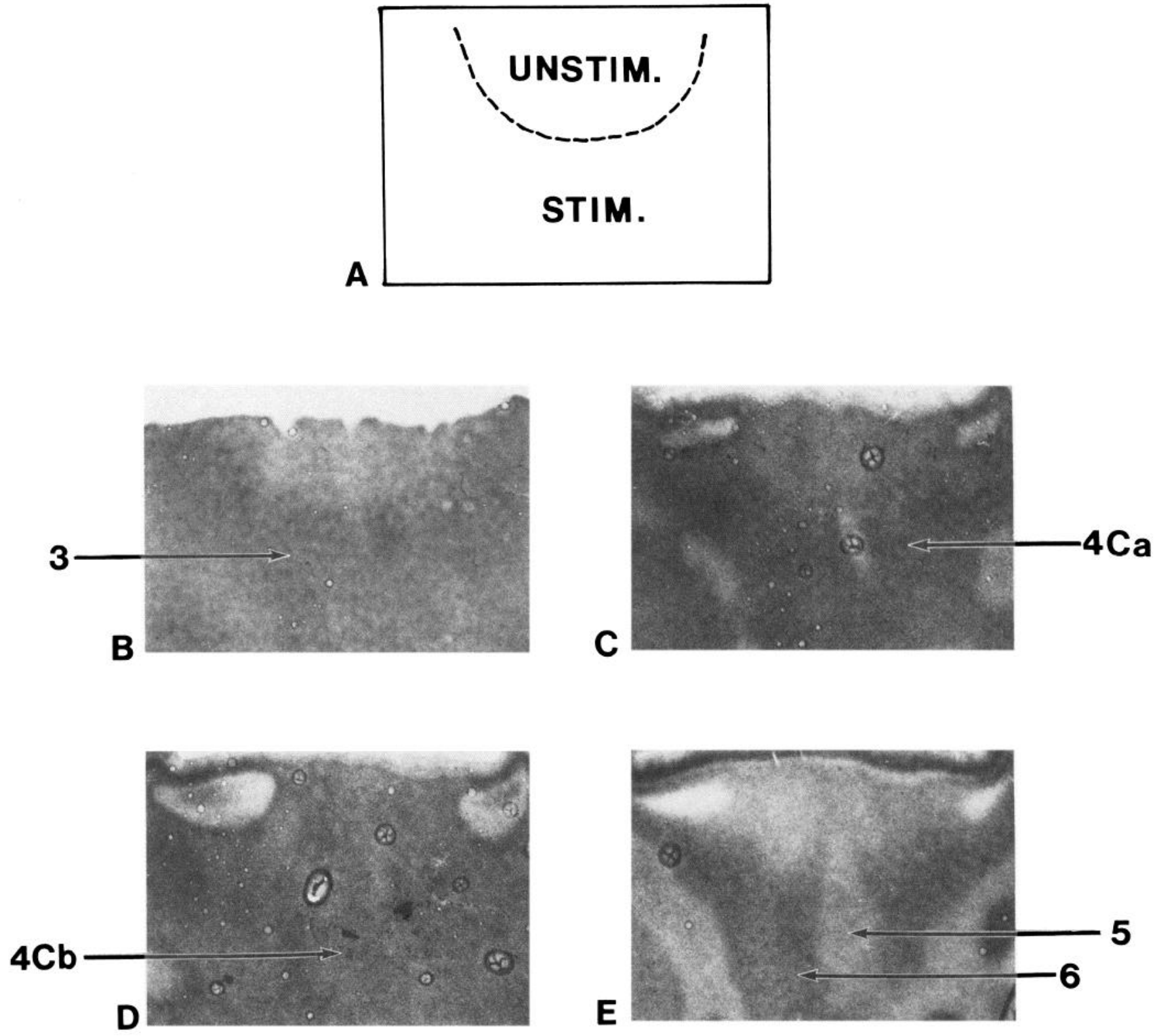

Figure 8. Laminar variation in the pattern of DG uptake produced by an $8 \%$ grating presented binocularly at all orientations. In order to discriminate stimulus-driven from baseline uptake, the stimulus grating was restricted to about $5^{\circ}$ in horizontal extent, so that baseline uptake could be compared to stimulus-driven uptake at the corresponding border in the parafoveal operculum. This border area is diagrammed with dashed lines in $A$. $B-F$, DG autoradiographs from successively deeper sections of the striate area corresponding to that in $A$. The pattern of stimulusdriven uptake in various striate layers is indicated by arrows. The relative levels of DG uptake in this case are similar to those found in monocular, single-orientation, $8 \%$ contrast cases (e.g., Figs. 2, 5), except that there appears to be somewhat more uptake in layers 3 and 5 (relative to other layers) than in the previous cases. However, the presence of relatively strong uptake in layers $4 \mathrm{Ca}(C)$ and $6(E)$, and the absence of measurable uptake in $4 \mathrm{Cb}(D)$, remains patent. Blob-shaped periodicities are evident in layers $2+3$, and to some extent in layer 6 . The levels of uptake in the unstimulated regions of layers $4 \mathrm{Ca}$ and $4 \mathrm{Cb}$ appear high in the photograph; this results from a higher overall uptake in the unstimulated state in these layers, exaggerated by the high-contrast photography. Scale bar, $5 \mathrm{~mm}$.

to area MT, and because layers $2+3$ project to $\mathrm{V} 2$, we would naturally expect that a grating of $8 \%$ contrast would produce significant DG uptake in area MT and less uptake in V2. Although our data from extrastriate cortex are somewhat scanty, these predictions appear to be borne out in areas MT and V2.

The notion that DG can be exploited in this way as a "functional HRP" rests on the logical necessity that a metabolically inactive area cannot activate areas to which it projects, whereas metabolically active areas generally feed this activity forward.
Consider the projections, which have been demonstrated so elegantly from the V1 blobs to half the V2 strips, and the parallel projections from the $\mathrm{V} 1$ interblob regions to the $\mathrm{V} 2$ interstrips (Livingstone and Hubel, 1984a, b). These projections were in fact presaged by the demonstration that DG uptake is high in (half) the V2 interstrips when it is high in the V1 blobs, and high in the V2 interstrips when high in the V1 interblobs (Tootell et al., 1983).

Although the descriptor "functional HRP" is newly coined 
(and perhaps overly glib), the idea that DG results have compelling connectional implications is familiar to many who work with the technique (e.g., Schwartz et al., 1979). One major advantage of the "functional HRP" technique is that it is (at least theoretically) infinitely transneuronal. This is related to another advantage, that DG results are broad in scope: functional activity throughout the whole brain is, of course, labeled in a single experiment. A final advantage of the technique is that it is noninvasive: the tissue of interest is not destroyed during the course of the labeling procedure. The major disadvantage of the technique, of course, is that, at the present level of technology, the DG technique cannot discriminate activation due to afferents from that due to efferents in a given region. Presumably the newer DG techniques promising cellular resolution will be able to eliminate this ambiguity (e.g., Sejnowski et al., 1980; Pilgrim and Wagner, 1981; Penreath et al., 1982; Hökfelt et al., 1983).

Since the present DG results furnish a valuable functional adjunct to strictly anatomical tracing experiments, we reexamined the pattern of DG uptake produced by other types of visual stimuli (see Tootell et al., 1988a-c) in order to confirm and extend our ideas about the flow of magnocellular and parvocellular information through striate cortex. Other visual stimuli besides low-contrast gratings also label either the magnocellular or the parvocellular input selectively in layer $4 \mathrm{Ca}$ or $4 \mathrm{Cb}$.

For instance, the DG results produced by low-contrast stimuli are in good accord with the results from stimulation with gratings of low $(<\sim 1 \mathrm{cycle} / \mathrm{deg})$ spatial frequencies at higher (e.g., $\sim 70 \%$ ) contrasts (Tootell et al., 1988d). As in the case of an $8 \%$ contrast grating, a high-contrast, low-spatial-frequency grating also produces a pattern of active DG uptake that is high in $4 \mathrm{Ca}$ but light or nonexistent in $4 \mathrm{Cb}$, indicating selective activation of the magnocellular, but not the parvocellular, layers. Presumably, the selective uptake in layer $4 \mathrm{Ca}$ produced by a low-spatialfrequency grating is due to the larger size of receptive fields that have been reported in the magnocellular and magnocellulardominated layers at a given eccentricity (e.g., Derrington and Lennie, 1984). The pattern of DG uptake produced by a highcontrast, low-spatial-frequency grating in layers $2+3$ is highest in the cytochrome oxidase blobs, and the uptake in these layers is fairly light overall. Thus, in 2 very different stimulus conditions (both producing selective uptake in the magnorecipient layer $4 \mathrm{Ca}$ ), there is a common pattern of uptake in layers $2+$ 3 which is selectively light and confined to the blobs.

Other evidence indicating a magno-parvo segregation comes from DG results in which the parvocellular-recipient layers (4A and $4 \mathrm{Cb}$ ) were preferentially activated. Spatially diffuse, equiluminant color-varying stimuli produce robust uptake in most striate layers (especially $4 \mathrm{~A}$ and $4 \mathrm{Cb}$ ), but only weak uptake in layers 4Ca and 4B (Tootell et al., 1980; Tootell and Silverman, 1981; see also Tootell et al., 1988c). Since the magnocellular layers have often been described as color-insensitive, the weak uptake in layer $4 \mathrm{Ca}$ in response to color-varying stimuli is entirely in accord with the projection from the magnocellular layers to striate 4Ca. Golgi staining (Lund, 1973; Lund and Boothe, 1975), electrophysiological mapping studies (Mitzdorf and Singer, 1979; Bullier and Henry, 1980), and HRP microinjections (Fitzpatrick et al., 1985) have also suggested a predominant projection from layer $4 \mathrm{Ca}$ to layer $4 \mathrm{~B}$, so the lack of color (parvo)-related uptake in layer $4 \mathrm{~B}$ is consistent with previous data. Layer 4B projects to cortical areas MT (Lund et al., 1976) and V3(D. Felleman, personal communication); in both of these extrastriate areas, color-specific cells have been reported to be either rare or absent altogether (e.g., Zeki, 1978; Maunsell and Van Essen, 1983). As in the DG results produced by other stimuli, it appears that the color-insensitive information from the magnocellular LGN layers is shunted through a fairly segregated striate pathway (via layers $4 \mathrm{Ca}$ and $4 \mathrm{~B}$ ) into cortical areas MT and V3.

Further evidence supporting a segregation of magno- and parvocellular information through striate cortex comes from the analysis of the cortical point image in DG retinotopic studies (see Tootell et al., 1988b). According to this DG evidence, there is a coarser retinotopic resolution in the magnorecipient striate layer $4 \mathrm{Ca}$ than that found in the parvorecipient layer $4 \mathrm{Cb}$. The DG retinotopic resolution in geniculorecipient layer $4 \mathrm{~B}$ is approximately as coarse as that seen in layer $4 \mathrm{Ca}$, and much coarser than that seen in layer $4 \mathrm{Cb}$; it is as if the retinotopic information in layer $4 \mathrm{Ca}$ were shunted in a straightforward way to layer $4 \mathrm{~B}$. However, the retinotopic resolution of DG maps in layer 3 is significantly finer than that in either of the magnocellular-dominated layers $4 \mathrm{Ca}$ or $4 \mathrm{~B}$, but is slightly degraded relative to that seen in parvocellular-recipient $4 \mathrm{Cb}$. This strongly suggests that the predominant input to striate layer 3 is derived from the parvocellular layers, and that to $4 \mathrm{~B}$ from the magnocellular layers.

In layers $2+3$, DG uptake produced by color-varying stimuli is often routed preferentially from presumptively parvocellular LGN layers into the blobs, probably via striate layer $4 \mathrm{Cb}$ (see Tootell et al., 1988c), but perhaps also via a weak direct projection (Horton, 1984). In this study we have also described DG evidence for a projection of magnocellular information into the blobs. Thus, there appears to be a convergence of magnocellularand parvocellular-derived input into the layer $2+3$ blobs; in this respect, the magnocellular and parvocellular streams appear joined. However, it is possible that some segregation of functional streams is still maintained at the cellular level, well below the resolution of the present deoxyglucose technique. Some support for this idea can be gleaned from the electrophysiological results of Livingstone and Hubel (1984a). According to their report, about a quarter of the nonoriented (presumptively blob) cells in layers $2+3$ are non-color cells. Many of these cells act like cells found in the magnocellular layers, on the basis of other criteria (Livingstone and Hubel, 1984a). Thus, these particular blob cells may be receiving inputs from the magnocellular layers via $4 \mathrm{Ca}$. The more numerous color cells in the blobs presumably derive their color information from the parvocellular LGN layers.

Certain stimuli with a lot of fine spatial detail (such as highspatial-frequency gratings) produce high DG uptake in the interblob regions, as well as high activation of layer $4 \mathrm{Cb}$ (e.g., Tootell et al., 1982, 1983, 1988d). No stimulus that produces sclective activation of layer $4 \mathrm{Ca}$ has produccd significant interblob uptake. This constitutes much of our evidence for the assumption that parvocellular (but not magnocellular) information projects to portions of layers $2+3$ between the blobs (the interblob areas).

Our ideas about the flow of magnocellular and parvocellular information through striate cortex are summarized in Figures 9 and 10. (These figures omit layers 5 and 6 , which in general project subcortically.) Information in the magnocellular stream passes through layers $4 \mathrm{Ca}$ and $4 \mathrm{~B}$ into $\mathrm{MT}$ and $\mathrm{V3}$, and weakly into the layers $2+3$ blobs and the thin V2 strips. A projection from layer $4 \mathrm{~B}$ to $\mathrm{V} 2$ was suggested after Figures 9 and 10 were drawn (D. H. Hubel and M. S. Livingstone, unpublished observations); such a projection would rationalize the presence of 
Figure 9. Summary diagram of DG evidence on the flow of magnocellular information through striate cortex. Information from the magnocellular LGN layers projects into $4 \mathrm{Ca}$, and from there it projects into all portions of $4 \mathrm{~B}$ and weakly into the blobs of layers 2 and 3 , and into blob-aligned portions of $4 \mathrm{~A}$. Though not shown, magnocellular information also projects strongly into layer 6 .

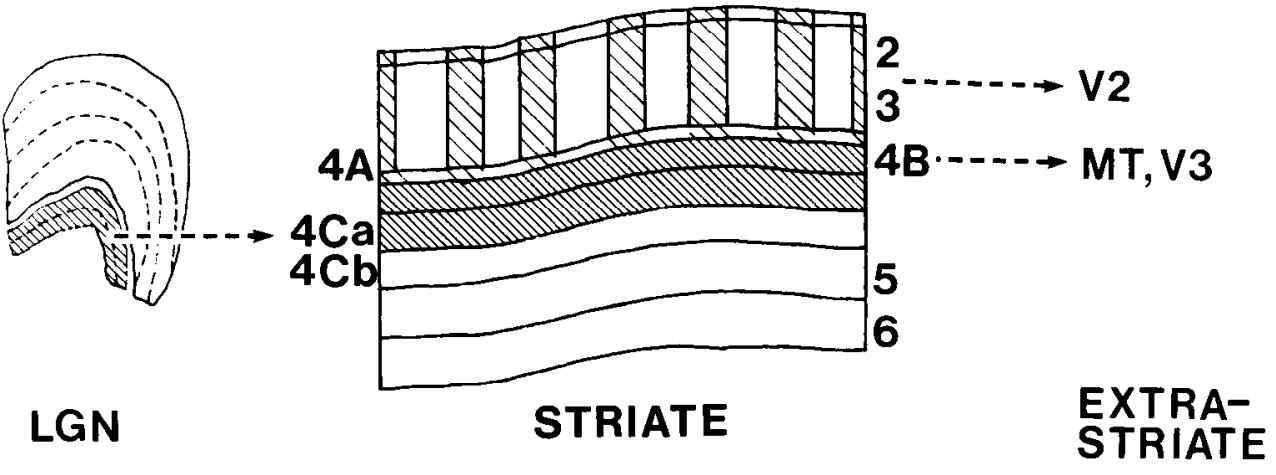

MAGNOCELLULAR STREAM significant input to $\mathrm{V} 2$ regions beyond the thin strips from striate layer 4B. The parvocellular stream passes through layers $4 \mathrm{Cb}$ and $4 \mathrm{~A}$, projects strongly into layers $2+3$, and from there into the thin stripes of area V2. This model in Figures 9 and 10 may turn out to be wrong in minor details, but the general flow of information seems clear-cut from the deoxyglucose results, as well as from previous Golgi (Lund, 1973; Lund and Boothe, 1975), electrophysiological (Mitzdorf and Singer, 1979; Bullier and Henry, 1980), and HRP (Blasdel et al., 1985; Fitzpatrick et al., 1985) studies. The data of Kaplan and Shapley (1986) also strongly imply that the parallel segregation of magnocellular and parvocellular information can be traced all the way back to the retina.

In a preliminary report, Merigan and Eskin (1985) stated that toxic exposure to acrylamide selectively eliminates the retinal afferents to the parvocellular LGN layers. In the cytochrome oxidase staining pattern in striate cortex of these animals, laycrs $4 \mathrm{~A}, 4 \mathrm{Cb}$, and 5 became quite pale; such a decrease in cytochrome oxidase activity is entirely consistent with the lack of magnocellular input to these layers demonstrated in the present DG results, as well as in previous studies. In these acrylamide-dosed monkeys, there was also a loss of contrast sensitivity, but this may have been due to a partial loss of function in the magnocellular LGN cells and/or to an interaction of the low-contrast decrements with spatial and temporal variables.

\section{Relationship of $D G$ contrast results to electrophysiology}

In limited comparisons of striate cells in layers $4 \mathrm{Ca}$ and $4 \mathrm{Cb}$, the contrast thresholds of layer 4Ca cells were lower than those in layer 4Cb cells (Blasdel and Fitzpatrick, 1984; Hawken and Parker, 1984). These unit results from $4 \mathrm{Ca}$ and $4 \mathrm{Cb}$ are entirely in accord with the contrast thresholds of the presumptive LGN afferents to these layers. The present DG results confirm the unit differences in layers $4 \mathrm{Ca}$ and $4 \mathrm{Cb}$, but the $\mathrm{DG}$ data also indicate a much cleaner anatomical segregation of contrast thresholds than is suggested by the unit results; the unit data show a certain amount of scatter in contrast threshold. The variation in the unit results may reflect minor ambiguities about exact laminar position when recording extracellularly from cells at some distance from the recording and marking electrode.

In a thorough analysis of cells from all layers (lumped together) of cat and monkey striate cortex, Albrecht and Hamilton
(1982) found that the contrast thresholds and the contrast gain function are extremely variable beween different cells. Different gain functions fitted different cells, and contrast thresholds in individual cells varied from below $1 \%$ to above $10 \%$ contrast. Although there was wide variability in the contrast gain function of each cell, the average semisaturation point for all cells occurred near $20 \%$ contrast. In the present DG study, the average semisaturation point also occurred near $20 \%$. However, in the present study, it was also obvious that the semisaturation point varied as a function of lamina. DG semisaturation points were about $20-35 \%$ contrast in parvocellular-dominated layers $(4 \mathrm{Cb}$, 2,3 , and 5), but closer to (or less than) $10 \%$ in magnocellulardominated layers $(4 \mathrm{Ca}, 4 \mathrm{~B}$, and 6$)$.

Presumably the laminar variation (visible in the DG results) accounts for some of the wide variability of semisaturation points seen in the earlier electrophysiological study (Albrecht and Hamilton, 1982). For instance, it is easy to imagine that a given cell in the interblob region of layer 3 or 5 would have a highcontrast threshold, and that a cell in layer 6 might have a low threshold. Similar considerations would also hold for variations in the contrast gain of individual cells in different layers.

In a study of the effects of adaptation on the contrast response function, Ohzawa et al. (1982) reported that cells in cat striate cortex (but not the LGN) adjust their dynamic range towards the range of available stimulus contrasts. According to this evidence, striate cells become more sensitive to lower-stimulus contrasts when adapted to low-contrast stimuli. When adapted to stimuli of higher contrast, the reverse occurs; cells become more insensitive to contrast.

Preliminary tests of single units in monkey striate cortex have shown no corresponding evidence for a dynamic shift in contrast sensitivity (G. Sclar, personal communication). At any rate, the DG evidence indicates that such a dynamic shift in the contrast sensitivity range is unlikely to be a major effect in monkey striate cortex, at least in the lower half of the contrast range. If the range of contrast sensitivity were to shift radically so as to match the range of available contrasts, then there would be little or no difference in the levels of DG uptake in response to stimulus quadrants of different contrast. From Figures 4 and 6 it is clear that this is not the obtained result. This is not entirely surprising, since there are a number of other differences between the contrast response properties of cat and monkey geniculocortical cells (Shapley and Perry, 1986). On the other hand, the evidence 


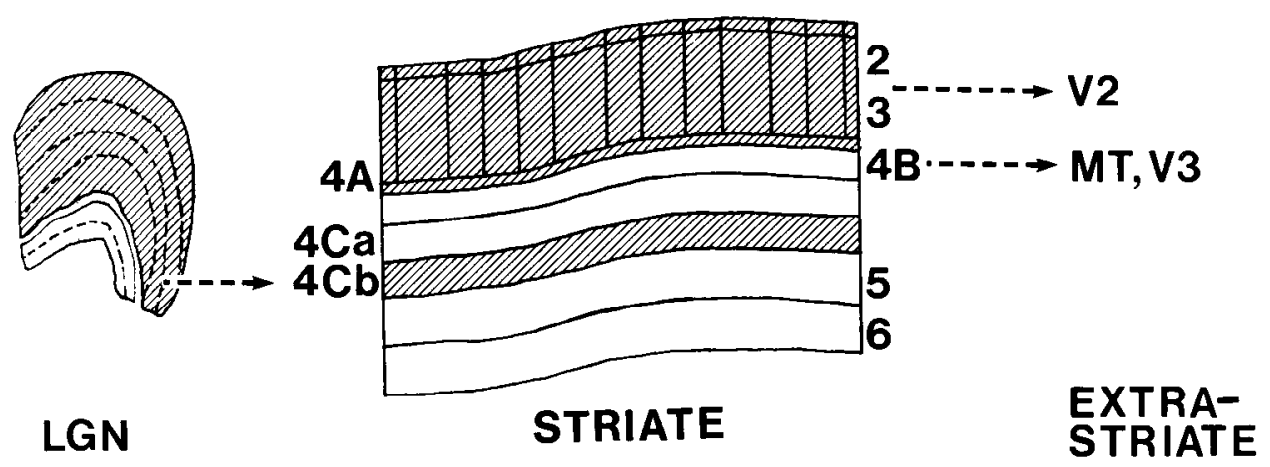

\section{PARVOCELLULAR} STREAM

that DG uptake increases in layer $4 \mathrm{Cb}$ (but not in other layers) between 40 and $100 \%$ argues for the possibility that contrast gain mechanisms may be operating at contrasts above $40 \%$ in the second-order parvo-dominated layers of striate cortex.

\section{Relationship of contrast results to psychophysics}

It is puzzling that contrast sensitivities differ so much between the parvocellular and magnocellular layers. Presumably the lowcontrast specialization of the magnocellular cells occurs in the natural world as well as in the laboratory. In the natural world, it might seem reasonable that the parvocellular cells (that is, most of the LGN cells) would reserve their dynamic range for stimulus contrasts above $10 \%$, since many of the achromatic stimulus contrasts in the world are well above $10 \%$. The magnoparvo difference in contrast sensitivity may simply reflect neural constraints that have not hcretofore demanded careful scrutiny. For instance, the greater color selectivity of the parvocellular cells may impose some mutually exclusive wiring constraints that make it impossible for these cells to achieve achromatic contrast sensitivities lower than about $10 \%$. Another possibility is that, since the magnocellular cells respond at higher temporal rates than those of parvocellular cells, they "need" to have a correspondingly higher-contrast sensitivity, in a sort of equalization-of-quantum-catch model.

The physiological and anatomical evidence for a parvocellular threshold at about $10 \%$ contrast has some interesting implications for visual psychophysics. Much, perhaps most, of the recent psychophysical literature uses contrast threshold measurements (at contrasts below 5\%) to characterize visual performance. Thus, the psychophysical data would appear to be based on the activity of magnocellular and magnocellular-recipient neurons. However, the magnocellular cells constitute a definite minority of the LGN cell population (e.g., Connolly and Van Essen, 1984). This magno-parvo cell imbalance is especially acute at the fovea, where it has been argued that there may be no magnocellular cells at all (e.g., Derrington and Lennie, 1984). Thus, the electrophysiological and anatomical data would suggest that psychophysical contrast threshold measurements characterize only a specific minority of the total population of cells along the geniculostriate pathway.

Based on the electrophysiological and functional anatomy data, one might expect to see an increased contrast threshold for foveal stimuli, and a discontinuity in the contrast response function near the threshold of parvocellular cells. However, this is not reflected in much of the psychophysical literature. Robson and Graham (1981) found contrast sensitivities to be highest in the fovea, regardless of spatial frequency. A number of psychophysical studies have examined the shape of the contrast function over a wide range of contrasts, and no discontinuity is obvious near 10-12\% contrast (Campbell and Kulikowski, 1966; Nachmias and Sansbury, 1974; Georgeson and Sullivan, 1975; Kulikowski, 1976; Tolhurst and Barfield, 1978; Cannon, 1979; Legge, 1981). This may reflect a relatively smooth interfacing of contrast information in the magnocellular and parvocellular channels.

However, because the psychophysical evidence predated the physiological evidence for 2 contrast sensitivity classes, it is also possible that a more detailed look at the contrast gain function might reveal a discontinuity near $10 \%$. Very recently, such a discontinuity in the psychophysical contrast discrimination function has been reported for a 4 cycle/deg grating (GouldSmith and Thomas, 1985). Tansley et al. (1983) have also reported a biphasic function relating border distinctness and achromatic contrast, with a break at about 5\% contrast; no corresponding discontinuity appears when using color contrast. Finally, contrast matching among differing spatial frequencies (Georgeson and Sullivan, 1975) gives quite different results at high and low contrasts.

It is also possible (at least theoretically) that some (previously undetected) parvocellular cells do respond to contrasts below $10 \%$, but at a low level of activity. Summation of such (hypothetical) parvocellular inputs could thus serve to equalize the magno-parvo contrast sensitivities at higher levels in the processing pathways. Such a result would rationalize the loss of contrast scnsitivity in acrylamide-dosed animals (Merrigan and Eskin, 1985) and be compatible with the psychophysical evidence against a low foveal contrast sensitivity and a discontinuity in the contrast response function near $10 \%$ contrast. Further investigation in both the psychophysical and electrophysiological realms is obviously needed.

\section{References}

Albrecht, D. G., and D. B. Hamilton (1982) Striate cortex of monkey and cat: Contrast response function. J. Neurophysiol. 48: 217-236. Blasdel, G. G., and D. Fitzpatrick (1984) Physiological organization 
of layer 4 in macaque striate cortex. J. Neurosci. 4: 880-895.

Blasdel, G. G., and J. S. Lund (1983) Termination of afferent axons in macaque striate cortex. J. Neurosci. 3: 1389-1413.

Blasdel, G. G., J. S. Lund, and D. Fitzpatrick (1985) Intrinsic connections of macaque striate cortex: Axonal projections of cells outside of lamina 4C. J. Neurosci. 5: 3350-3369.

Bullier, J., and G. H. Henry (1980) Ordinal position and afferent input of neurons in monkey striate cortex. J. Comp. Neurol. 193: 913-935.

Burkhalter, A., and D. C. Van Essen (1982) Processing of color, form and disparity in visual areas V2 and VP of ventral extrastriate cortex in the macaque. Soc. Neurosci. Abstr. 8: 881.

Campbell, F. W., and J. J. Kulikowski (1966) Orientation selectivity of the human visual systems. J. Physiol. (Lond.) 187: 437-445.

Cannon, D. W., Jr. (1979) Contrast sensation a linear function of stimulus contrast. Vision Res. 19: 1045-1052.

Connolly, M., and D. Van Essen (1984) The representation of the visual field in parvicellular and magnocellular layers of the lateral geniculate nucleus in the macaque monkey. J. Comp. Neurol, 226: 544-564.

Derrington, A. M., and P. Lennie (1984) Spatial and temporal contrast sensitivities of neurons in lateral geniculate nucleus of macaque. $J$. Physiol. (Lond.) 357: 219-240.

De Valois, R. L., C. J. Smith, A. Kanoly, and S. T. Kitai (1958) Electric responses of primate visual system: $I$. Different layers of macaque lateral geniculate nucleus. J. Comp. Physiol. Psychol. 51: 662-668.

DeYoe, E. A., and D. C. Van Essen (1985) Segregation of efferent connections and receptive field properties in visual area V2 of the macaque. Nature 317: 58-61.

Dreher, B., Y. Fukada, and R. W. Rodieck (1976) Identification, classification and anatomical segregation of cells with $\mathrm{X}$-like and $\mathrm{Y}$-like properties in the lateral geniculate nucleus of old-world primates. $J$. Physiol. (Lond.) 258: 433-452.

Fisken, R. A., L. J. Garey, and T. P. S. Powell (1975) The intrinsic association and commissural connections of area 17 of the visual cortex. Phil. Trans. R. Soc. Lond. [Biol.] 272: 487-536.

Fitzpatrick, D., J. S. Lund, and G. G. Blasdel (1985) Intrinsic connections of macaque striate cortex: Axonal projections of cells outside of lamina 4C. J. Neurosci. 5: 3350-3369.

Georgeson, M. A., and G. D. Sullivan (1975) Contrast constancy: Deblurring in human vision by spatial frequency channels. J. Physiol. (Lond.) 252: 627-656.

Gould-Smith, B., and J. P. Thomas (1985) Contrast discrimination: Nonmonotonic psychometric function suggests dual mechanisms. Invest. Ophthalmol. Vis. Sci. (Suppl.) 26: 138.

Hawken, M. J., and A. J. Parker (1984) Contrast sensitivity and orientation selectivity in lamina IV of the striate cortex of old world monkeys. Exp. Brain Res. 54: 367-372.

Hendrickson, A. E., and J. R. Wilson (1979) A difference in the [14C] deoxyglucose autoradiographic patterns in striate cortex between $\mathrm{Ma}$ caca and Saimiri monkeys following monocular stimulation. Brain Res. 170: 353-358.

Hendrickson, A. E., J. R. Wilson, and M. P. Ogren (1978) The neuroanatomical organization of pathways between dorsal lateral geniculate nucleus and visual cortex in old and new world primates. $J$. Comp. Neurol. 182: 123-136.

Hicks, T. P., B. B. Lee, and T. R. Vidyasagar (1983) The responses of cells in macaque lateral geniculate nucleus to sinusoidal gratings. J. Physiol. (Lond.) 337: 183-200.

Hökfelt, T., C. B. Smith, A. Peters, G. Norell, A. Crane, M. Brownstein, and L. Sokoloff (1983) Improved resolution of the 2-deoxy-d-glucose technique. Brain Res. 289: 311-316.

Horton, J. C. (1984) Cytochrome oxidase patches: A new cytoarchitectonic feature of monkey visual cortex. Phil. Trans. R. Soc. Lond. [Biol.] 304: 199-253.

Hubel, D. H., and T. N. Wiesel (1972) Laminar and columnar distribution of geniculo-cortical fibers in macaque monkey. J. Comp. Neurol. 146: 421-450.

Kaplan, E., and R. M. Shapley (1982) X and $Y$ cells in the lateral geniculate nucleus of macaque monkey. J. Physiol. (Lond.) 330: 125143.

Kaplan, E., and R. M. Shapley (1986) The primate retina contains two types of ganglion cells, with high and low contrast sensitivity. Proc. Natl. Acad. Sci. USA 83: 2755-2757.

Kennedy, C., M. H. Des Rosiers, O. Sakurada, O. Shinohara, M. Reivich, J. W. Jehle, and L. Sokoloff (1976) Metabolic mapping of the primary visual system of the monkey by means of the autoradiographic [14C] deoxyglucose technique. Proc. Natl. Acad. Sci. USA 73: $4230-4234$.

Kulikowski, J. J. (1976) Effective contrast constancy and linearity of contrast sensation. Vision Res. 16: 1419-1432.

Legge, M. W. (1981) A power law for contrast discrimination. Vision Res. 21: 457-467.

Livingstone, M. S., and D. H. Hubel (1984a) Anatomy and physiology of a color system in the primate visual cortex. J. Neurosci. 4: 309356.

Livingstone, M. S., and D. H. Hubel (1984b) Specificity of intrinsic connections in primary visual cortex. J. Neurosci. 4: 309-356.

Lund, J. S. (1973) Organization of neurons in the visual cortex, area 17 , of the monkey (Macaca mulatta). J. Comp. Neurol. 147: 455496.

Lund, J. S., and R. G. Boothe (1975) Interlaminar connections and pyramidal neuron organization in the visual cortex, area 17 , of the macaque monkey. J. Comp. Neurol. 159: 305-334.

Lund, J. S., R. D. Lund, A. E. Hendrickson, A. H. Bunt, and A. F. Fuchs (1976) The origin of efferent pathways from the primary visual cortex, area 17 , of the macaque, monkey as shown by retrograde transport of horseradish peroxidase. J. Comp. Neurol. 164: 287-304.

Maunsell, J. H. R., and D. C. Van Essen (1983) Functional properties of neurons in middle temporal visual area of the macaque monkey I. Selectivity for stimulus direction, speed and orientation. J. Neurophysiol. 49: 1127-1147.

Merigan, W. H., and T. A. Eskin (1985) Vision in primates with severe loss of $\mathrm{Pb}$ retinal ganglion cells. Invest. Ophthalmol. Vis. Sci. (Suppl.) 26: 12 .

Mitzdorf, U., and W. Singer (1979) Excitatory synaptic ensemble properties in the visual cortex of the macaque monkey: A current source density analysis of clectrically cvoked potentials. J. Comp. Neurol. 187: 71-84.

Nachmias, J., and R. Sansbury (1974) Grating contrast discrimination may be better than detection. Vision Res. 14: 1039-1042.

Ohzawa, I. G., G. Sclar, and R. D. Freeman (1982) Contrast gain control in the cat visual cortex. Nature 298: 266-268.

Penreath, V. W., L. H. Seal, and M. A. Kai-Kai (1982) Incorporation of [3H] 2-deoxyglucose into glycogen in nervous tissue. Neuroscience $7: 759-767$.

Pilgrim, C. H., and H.-J. Wagner (1981) Improving the resolution of the 2-deoxy-D-glucose method. J. Histochem. 29: 190-194.

Robson, J. G., and N. Graham (1981) Probability summation and regional variations in contrast sensitivity across the visual field. Vision Res. $21: 409-418$.

Schiller, P. H., and J. G. Malpeli (1978) Functional spccificity of lateral geniculate nucleus laminae of the rhesus monkey. J. Neurophysiol. 41: 788-797.

Schwartz, W. J., C. B. Smith, L. Davidsen, H. Savaki, L. Sokoloff, M. Mata, D. J. Fink, and H. Gainer (1979) Metabolic mapping of functional activity in the hypothalamo-hypophyseal system in the rat. Science 205: 723-725.

Sejnowski, T. J., S. C. Reingold, D. Kelly, and A. Gelperin (1980) Localization of [3H]-2-deoxyglucose in single molluscan neurons. $\mathrm{Na}$ ture 287: 449-451.

Shapley, R., and V. H. Perry (1986) Cat and monkey retinal ganglion cells and their visual functional roles. Trends Neurosci. 9: 229-235.

Sperling, H. G., M. L. J. Crawford, and S. Espinoza (1978) Threshold spectral sensitivity of single neurons in the lateral geniculate nucleus of performing monkeys. Mod. Probl. Ophthalmol. 19: 2-18.

Switkes, E., R. B. H. Tootell, and R. L. De Valois (1986) Picture processing techniques applied to autoradiographic studies of visual cortex. J. Neurosci. Methods 15: 269-280.

Tansley, B. W., A. W. Robertson, and K. E. Maughan (1983) Chromatic and achromatic border perception: $A$ two-cone model accounts for suprathreshold border distinctness judgements and cortical pattern-evoked response amplitudes to the same stimuli. In Colour Vision, J. Mollon and R. T. Sharpe, eds., pp. 445-453, Academic, Orlando, FL.

Tolhurst, D. J., and L. P. Barfield (1978) Interactions between spatial frequency channels. Vision Res. 18: 951-958.

Tootell, R. B. H., and M. S. Silverman (1981) A comparison of cytochrome oxidase and deoxyglucose patterns in macaque visual cortex. Soc. Neurosci. Abstr. 7: 356.

Tootell, R. B. H., M. S. Silverman, and R. L. De Valois (1980) Color- 
dependent deoxyglucose patterns within macaque striate cortex. Invest. Ophthalmol. Vis. Sci. (Suppl.) 19: 226.

Tootell, R. B. H., M. S. Silverman, E. Switkes, and R. L. De Valois (1982) Organization of cortical modules. Soc. Neurosci. Abstr. 8: 707.

Tootell, R. B. H., M. S. Silverman, R. L. De Valois, and G. H. Jacobs (1983) Functional organization of the second cortical visual area of primates. Science 220:737-739.

Tootell, R. B. H., S. L. Hamilton, M. S. Silverman, and E. Switkes (1988a) Functional anatomy of macaque striate cortex. I. Ocular dominance, binocular interactions, and baseline conditions. J. Neurosci. 8: $1500-1530$.

Tootell, R. B. H., E. Switkes, M. S. Silverman, and S. L. Hamilton (1988b) Functional anatomy of macaque striate cortex. II. Retinotopic organization. J. Neurosci. 8: 1531-1568.

Tootell, R. B. H., M. S. Silverman, S. L. Hamilton, R. L. De Valois, and E. Switkes (1988c) Functional anatomy of macaque striate cortex. III. Color. J. Neurosci. 8: 1569-1593.

Tootell, R. B. H., M. S. Silverman, S. L. Hamilton, E. Switkes, and R.
L. De Valois (1988d) Functional anatomy of macaque striate cortex. V. Spatial frequency. J. Neurosci. 8: 1610-1624.

Van Essen, D. C., and J. H. R. Maunsell (1983) Hierarchical organization and functional streams in the visual cortex. Trends Neurosci. 6: $370-374$

Van Essen, D. C., J. H. R. Maunsell, and J. L. Bixby (1981) The middle temporal visual area in the macaque: Myeloarchitecture, connections, functional properties and topographical organization. J. Comp. Neurol. 199: 293-326.

Wiesel, T. N., and D. H. Hubel (1966) Laminar and columnar distribution of geniculocortical fibers in the macaque monkey. J. Neurophysiol. 29: 1115-1156.

Zeki, S. M. (1974) Functional organization of a visual area in the posterior bank of the superior temporal sulcus of the rhesus monkey. J. Physiol. (Lond.) 236: 549-573.

Zeki, S. M. (1978) Uniformity and diversity of structure and function in rhesus monkey prestriate visual cortex. J. Physiol. (Lond.) 277: 273-290. 